\title{
Geogenic versus Anthropogenic Metals and Metalloids
}

\author{
Jeffrey Hess, Mark Sorensen \\ Gilbane Environmental, Concord, USA \\ Email: j.hess@gilbaneco.com
}

How to cite this paper: Hess, J. and Sorensen, M. (2018) Geogenic versus Anthropogenic Metals and Metalloids. Journal of Environmental Protection, 9, 468-500. https://doi.org/10.4236/jep.2018.95029

Received: March 16, 2018

Accepted: May 11, 2018

Published: May 14, 2018

Copyright $\odot 2018$ by authors and Scientific Research Publishing Inc. This work is licensed under the Creative Commons Attribution International License (CC BY 4.0).

http://creativecommons.org/licenses/by/4.0/

\begin{abstract}
Developing a successful strategy for investigating and remediating sites potentially impacted by metals (such as chromium $[\mathrm{Cr}]$, copper $[\mathrm{Cu}]$, lead $[\mathrm{Pb}]$, nickel [Ni], and zinc $[\mathrm{Zn}]$ ) and metalloids (such as arsenic [As] and antimony [Sb]) can be challenging. These elements occur naturally and geologic materials can be enriched in these elements by natural processes. Conventional environmental investigative methods do not readily support evaluating whether metals and metalloids are geogenic (naturally occurring) or anthropogenic (from human action), or allow differentiating multiple anthropogenic sources. Geochemical methods can potentially determine whether metals and metalloids are geogenic or anthropogenic, and differentiate between possible anthropogenic sources. Conventional geochemical methods include whole-rock analysis using $\mathrm{x}$-ray fluorescence (XRF) to yield elemental concentrations; optical petrography and powder $\mathrm{x}$-ray diffraction $(\mathrm{XRD})$ to determine mineral phases present; and electron microprobe (EMP) to confirm both mineral phases present and the distribution of elements within mineral phases and the rock matrix. These methods, with the exception of the EMP, can be performed in the field using portable equipment, allowing for relatively rapid assessment of sites. A case study is presented in which these techniques were successfully utilized to demonstrate, using multiple lines of evidence, that metals and metalloids present in subsurface fractured rock were geogenic and unrelated to recent industrial operations.
\end{abstract}

\section{Keywords}

Geogenic, Anthropogenic, Metals, Metalloids, Geochemical

\section{Introduction}

Developing a successful strategy for investigating and remediating sites poten- 
tially impacted by metals (such as chromium [Cr], copper [Cu], lead [Pb], nickel [Ni], and zinc [Zn]) and metalloids (such as arsenic [As] and antimony [Sb]) can be challenging. These elements occur naturally and geologic materials can be enriched in these elements by natural processes (geogenic). The U.S. Environmental Protection Agency (EPA) provides guidance on the role of background in the cleanup process [1], and the determination of background levels of metals and other chemicals in soils [2]. These guidance documents emphasize the calculation of total risk from a site from all contaminants. It is then the responsibility of the property owner or responsible party to demonstrate the contribution to the total risk by naturally occurring (geogenic) elements. However, the prescribed regulatory approach typically results in a sampling effort to support statistically derived background values, rather than a thorough geochemical evaluation of the origin of metals and metalloids. A geochemical approach may be more appropriate at complex sites where metals and metalloids are suspected to have been released, especially in cases where the site hosts a geologic formation with naturally high metal or metalloid concentrations, or evidence of mineralization is observed. Such conditions call for a geochemical background assessment to characterize the metal or metalloid-rich formation, and/or the mineralized geological formations. Such characterization often involves building a case for geogenic origin based on multiple lines of evidence, such as identifying mineralization or hydrothermal activity, specifying the existence and distribution of metal- or metalloid-rich minerals, their conditions of formation (e.g., temperature, pressure), and their mechanisms of formation (e.g., geothermal deposition, emanations along a fault zone).

Without a geochemical evaluation of such factors, the prescribed regulatory approach of a "sampling-only" evaluation of background focused on statistically derived background values may obscure rather than illuminate the issue of the origin of the anomalous levels of metals and metalloids. Additionally, the conventional environmental investigative approach to sites with metals and metalloids often does not provide sufficient information to assess relative contributions from geogenic and anthropogenic sources, as it utilizes EPA-approved analytical methods whose extraction methods can recover only a portion of the metals and metalloids present [3], and analyses that provide little to no information on the nature and distribution of the metals and metalloids in the sample.

\section{Geochemical Approach and Conceptual Site Model}

To evaluate whether metals and metalloids present in the environment are geogenic or anthropogenic, geochemical methods common to the mineral exploration and mining industry can be used. The application of these methods is based on established scientific principles, is defensible, and is repeatable. As similar to many technical undertakings, experience with the prescribed methods and, in this case, geochemistry and mineralogy, improves the outcome of the effort. The primary geochemical methods presented below can be performed in the field 
using portable equipment. Other specialized methods may be necessary and appropriate to provide additional lines of evidence require the use of laboratory-based equipment and experienced operators. In particular, use of an electron microprobe (EMP) can be beneficial and is complementary to the primary geochemical methods presented below.

As with any investigation, an important first step is to develop a conceptual site model (CSM). The CSM should provide detailed information on the geologic framework for the area where the site is located, regional or local mineralization, records of historic or current mineral extraction, and available local geology. From this CSM, the correct study questions can be developed which will support the design of the geochemical study. For example, the case study site is located in an area with historic mining-related activities in the San Gabriel Mountains of southern California. A wealth of geological, mineralogical and historical information was available in literature that helped with developing the study questions and ultimately designing an appropriate geochemical investigative program. Additionally, significant industrial activities had occurred in the area, which were also documented and available for evaluation. Thus, a key step in developing the CSM is a thorough literature review, including visiting local historical societies, seeking out others who may be knowledgeable on the history of the area where the site is located, and interviewing people knowledgeable in past industrial operations at the site and in the surrounding area.

\section{Geochemical Methods}

The primary geochemical methods include visual examination of outcrops and hand samples for petrographic classification and tentative mineral phase identification, whole-rock and mineral-phase analysis using $\mathrm{x}$-ray fluorescence (XRF) to yield elemental concentrations, powder $\mathrm{x}$-ray diffraction (XRD) to identify primary mineral phases, and transmitted and reflected polarized light microscopy (PLM) to identify mineral phases and textures. The findings from the aforementioned geochemical methods can be further supported, if needed, by analysis of selected samples using EMP. The geochemical methods are discussed below, and examples of their use in supporting the findings of the case study are presented.

\subsection{Visual Classification of Rocks and Minerals}

Identification of rocks, and especially minerals, is a central task in the geochemical approach described in this paper. Field examination and identification can provide important information in addressing the issues identified in the CSM. Specifically, minerals have specific and relatively narrow ranges of composition, and many of them contain metals and metalloids of concern with regard to impacts on human health or the environment. Further, minerals commonly form under specific conditions of temperature, pressure, and reduction-oxidation (redox) conditions that differ from those that prevail near the earth's surface, 
where temperatures and pressures are relatively low, and redox conditions are generally oxidizing. The first and most direct method of identifying rocks and minerals is through field observation of surface exposures and near-surface excavations or drill cores. Many rocks and minerals can be identified in the field. Samples are then collected for confirmation of their identification and for further processing using the various methods as described in the supplemental material. The geologic observations are recorded; larger-scale features such as faults, folds, or large veins can be documented with photographs.

For example, with the selected case study site described in the following paragraphs, numerous outcrops at the site and surrounding area were examined, along with the exposed wall rock within excavations onsite, and drill cores from borings onsite and offsite. Many of the rocks observed on and near the site were felsic rocks, consistent with Mesozoic-era mylonitized granites and diorites, and Precambrian-era gneisses constituting the primary rock types in the area [4]. Ultramafic rocks, although not widely reported in the San Gabriel Mountains, were present, as serpentinized peridotite, in one small outcrop, and also at the base of an excavation and in drill cores. Hundreds of hand samples were collected that represented the diverse lithology of the area, and were representative of alteration observed in the outcrops, excavations, and drill core from on and near the site. Visual examination of the hand samples included examination using a hand lens under natural light to determine color, texture and major mineral phases, and testing with a hand magnet for magnetism (useful for determining the existence and degree of serpentinization of ultramafic rocks). Hand samples were also field screened using a handheld XRF to identify those samples containing the highest concentrations of the metals and metalloids of interest, for further analysis.

Metal and metalloid content varies significantly by rock type, especially for the rock types encountered at the case study site. For example, the average felsic rock (e.g., granite) worldwide has an average of 8 milligrams per kilogram $(\mathrm{mg} / \mathrm{kg})$ of $\mathrm{Cr}$ and $25 \mathrm{mg} / \mathrm{kg}$ of Ni. In contrast, the average ultramafic rock contains an average of $2000 \mathrm{mg} / \mathrm{kg}$ each of $\mathrm{Cr}$ and $\mathrm{Ni}$ [5], roughly two orders of magnitude higher than their concentrations in granite. At and near the site, the mean concentration of $\mathrm{Cr}$ in samples of unaltered felsic rocks was $30 \mathrm{mg} / \mathrm{kg}$, and the mean concentration in samples of unaltered ultramafic rocks was 2280 $\mathrm{mg} / \mathrm{kg}$ (based on XRF analysis performed as described in Section 3.2). For Ni the corresponding values were $10.7 \mathrm{mg} / \mathrm{kg}$ in felsic rocks, and $1080 \mathrm{mg} / \mathrm{kg}$ in ultramafic rocks.

The presence primarily of granite and granitic gneiss with subordinate amounts of serpentinite at the case study site was significant in determining background metal concentrations. As noted above, concentrations of $\mathrm{Cr}$ and $\mathrm{Ni}$ in granite differ from those in serpentinite by two orders of magnitude, respectively. This bimodal distribution of $\mathrm{Cr}$ and $\mathrm{Ni}$ in site rocks (and soils) meant that statistically meaningful determinations of background for $\mathrm{Cr}$ and $\mathrm{Ni}$ could not be made independently of reference to site geology; instead, background levels of these and 
most other metals and metalloids are specific to the geologic formation. Common approaches to background determination, such as collecting limited numbers of soil or rock samples, may not even include samples located in the serpentinite area, which had a limited areal distribution at the site prior to the excavation. Even if one or more samples were collected by chance in the serpentinite areas, a second important limitation of a "sampling-only" background assessment is that while the bimodal distribution of concentrations would be revealed, it could be misinterpreted as contamination. At other sites, bimodal distribution is often explicitly identified as a possible indicator of contamination. For these reasons, and especially for metals and metalloids, geologic context and careful sampling are critical in evaluating the origin of anomalously elevated metals or metalloids at an environmental site under investigation. In many cases a background study that employs a "sampling-only" approach is inappropriate.

Another key field geologic observation of the case study was that many of the lithologic samples with elevated concentrations of metals and metalloids were associated with the most weathered samples, particularly specimens with abundant orange to yellow-brown coatings of hydrous iron $(\mathrm{Fe})$ oxides along fracture and surfaces. Hydrous $\mathrm{Fe}$ oxides are highly effective sorbents of many metals and metalloids, including $\mathrm{As}$, $\mathrm{Sb}$, barium $(\mathrm{Ba}), \mathrm{Cu}, \mathrm{Pb}$, and $\mathrm{Zn}$.

\subsection{Elemental Analysis by X-Ray Fluorescence (XRF)}

The XRF is an analytical technique used to determine elemental concentrations in a sample. XRF uses an $\mathrm{x}$-ray beam directed at a sample to displace electrons from their orbital positions in atoms within the sample, each time releasing energy that is characteristic of a specific element. The XRF instrument detects the released energies and provides a listing of the elements present and their concentrations within the sample. XRF analysis, using EPA Method 6200 [6], has a distinct advantage over the wet chemistry methods commonly employed in environmental investigations, such as EPA Method 6010B for metals and metalloids, in that XRF is able to detect the presence of elements in any form, and thus reports total concentrations of those elements present in the sample. In contrast, EPA Method 3050B/6010B uses acid (a combination of nitric acid, hydrogen peroxide, hydrochloric acid) digestion with heat to extract the metals from the sample. While this method is considered a strong acid digestion process suitable for elements that could become "environmentally available" and thus well suited for evaluation of potential risk to human and ecological receptors, it is not considered a total digestion method [3]. Some remaining amounts of the elements of interest are likely present in mineral forms that are resistant to this extraction method, resulting in the wet chemistry method typically under-reporting the total concentrations of elements present in forms resistant to chemical extraction techniques. Other more aggressive extraction methods are available, such as the 4-acid digestion technique used by the U.S. Geological Survey, but even this more aggressive method is subject to significant limitations that prevent the 
complete extraction of some metals in "refractory" minerals (e.g., $\mathrm{Cr}$ in chromite and Ba in barite) (https://crustal.usgs.gov/laboratories/icpms/solution.html).

The effects of the incomplete extraction of elements using the wet chemistry method versus the XRF method are illustrated in Figure 1 for $\mathrm{Cr}$ and Ni. This graph was created with results from the site featured in the case study presented in Section 4. As shown in the graphs, the results for $\mathrm{Cr}$ and $\mathrm{Ni}$ are generally much higher by XRF than by the wet chemistry method mentioned above. The greater variation in the $\mathrm{Cr}$ results may be from a greater proportion of the metal being present in the form of chromite or other refractory mineral.

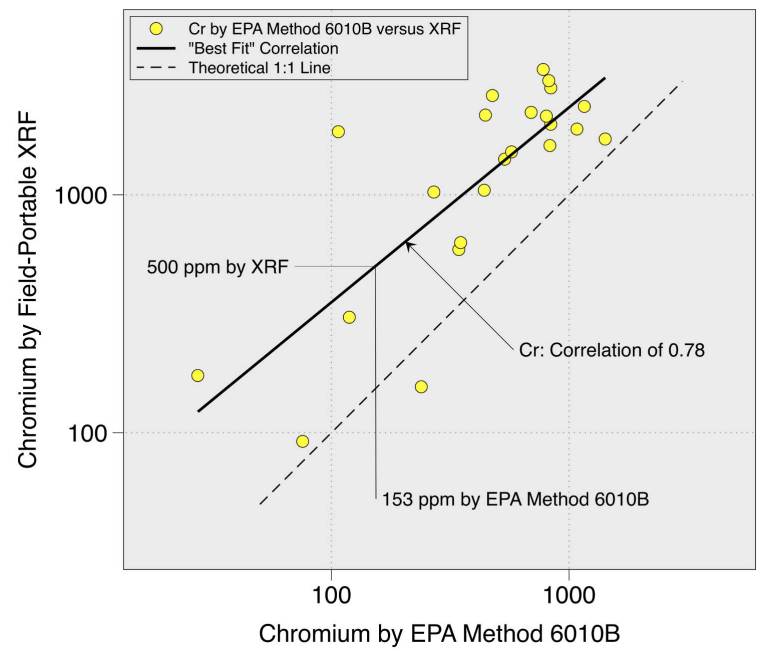

(a)

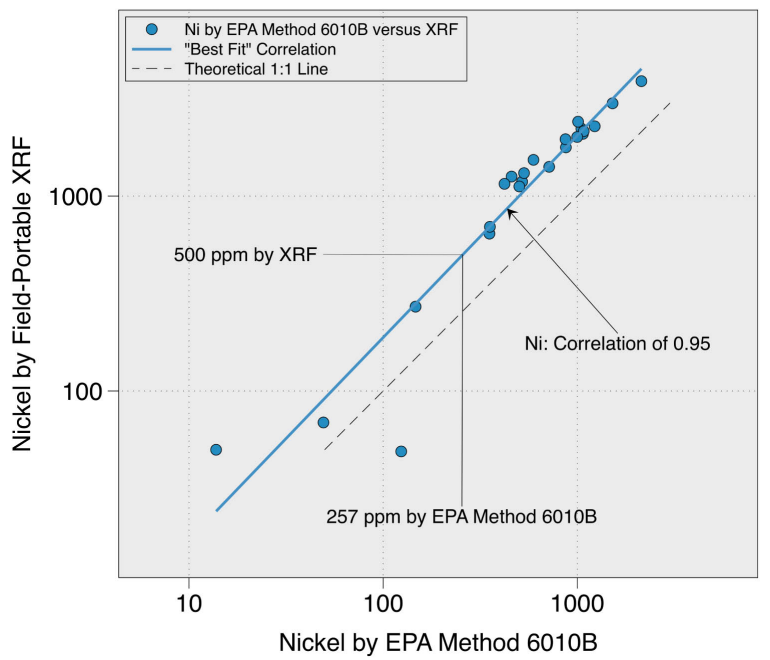

(b)

Figure 1. Portable XRF results compared to wet chemistry (EPA Method 6010B) results for $\mathrm{Cr}$ (a) and $\mathrm{Ni} \mathrm{(b).} \mathrm{In} \mathrm{each} \mathrm{case,} \mathrm{results} \mathrm{for} \mathrm{all} \mathrm{but} \mathrm{one} \mathrm{sample} \mathrm{fall} \mathrm{significantly} \mathrm{above} \mathrm{the}$ 1:1 correlation line, indicating that results were consistently higher using XRF than wet chemistry methods. The greater contrast for $\mathrm{Cr}$ is consistent with the common presence of chromite in site samples, a mineral that is resistant to the chemical extraction step needed for wet chemistry analysis. In contrast, the XRF method is capable of detecting all forms of $\mathrm{Cr}$ in a sample, regardless of the minerals that contain $\mathrm{Cr}$. 
Around 250 samples from the site and surrounding area were analyzed using a portable Olympus Corporation (Olympus) X-5000 XRF unit for major and minor elements. Most of these samples represented rock samples, but some of the samples represented mineral coatings scraped from rock surfaces.

\subsection{Mineral-Phase Identification by X-Ray Diffraction (XRD)}

$\mathrm{XRD}$ is an analytical technique used to identify the primary mineral phases present in a sample. XRD uses an x-ray beam directed at a finely ground and homogenized sample. The beam interacts with the crystalline structure of minerals, creating diffraction patterns recorded by the instrument's detector. These diffraction patterns can be interpreted to provide unit cell dimensions, and ultimately the identity of the mineral phases present.

Over 60 samples of rocks and mineral coatings from the case study site were analyzed by XRD to support determination of primary mineralogy. The XRD proved valuable in identifying fine alteration products such as clinochlore (a variety of chlorite), characteristic of chloritic alteration of an ultramafic rock, and other fine-grained minerals such as kaolinite and montmorillonite, not easily identifiable by other means (see Section 4.2.4). The XRD results, used in conjunction with XRF results and microscopic examination of thin sections using PLM, support the identification of minerals and enhance the interpretation of hydrothermally altered or weathered rocks.

\subsection{Mineral Identification by Optical Petrography}

Examination using PLM can provide significant information on both translucent and opaque minerals present in samples. Further, through the examination of mineral textures, it is often possible to define the nature and sequence of rock-forming and rock-altering events (at the case study site, these processes included igneous crystallization of primary minerals, followed by transformation by metamorphism, hydrothermal alteration, and finally uplift and consequent weathering upon exposure near and at the ground surface).

For the case study site, the local presence of ore minerals (e.g., metal sulfides and oxides such as chalcopyrite [ $\mathrm{Cu}-\mathrm{Fe}$ sulfide] and magnetite [an $\mathrm{Fe}$ oxide]) prompted the preparation of polished thin sections, for two purposes: 1) viewing and identifying ore minerals, most of which are opaque, under reflected light, using the PLM; and 2) determining metal concentrations and verifying our mineral identifications using the EMP. Figure 2 is a photomicrograph using reflected light in the PLM, and shows how various minerals have contrasting appearances, thereby enabling identification. Three opaque minerals (pentlandite, pyrite, and magnetite) are visible in a matrix of silicate minerals in a sample of serpentinized peridotite from the case study site.

In addition to identifying minerals in rock specimens, a key advantage of using a PLM is that rock and mineral textures can be studied in detail. Texture refers to the size, shape, and arrangement of minerals, including patterns that can 


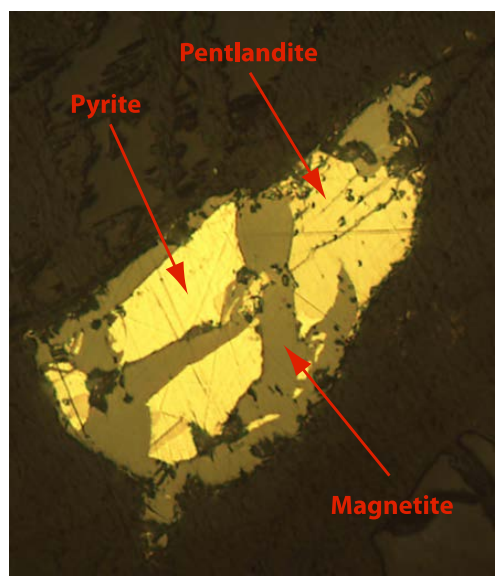

Figure 2. Pentlandite, pyrite and magnetite under PLM. Magnetite cuts across and surrounds sulfide minerals pentlandite and pyrite, and thus was introduced after the sulfides.

show the sequence of mineral deposition. Such patterns include cross-cutting relationships (later minerals deposited along fractures will cross-cut earlier-formed minerals and fractures); concentric growth (later-formed minerals can symmetrically coat the outer margins of earlier-formed mineral grains); and mineral-filling sequence in wide veins or between intact mineral grains (early minerals grow at the edges of a fracture or open space, while later minerals grow in the remaining spaces in the interior of the fracture or open space).

During the case study site activities, at least 70 samples were examined using PLM under plane-polarized and cross-polarized light in both the transmitted light mode and reflected light mode to determine mineral phases, and to observe textures and other features of the rock. Observations were used in conjunction with the hand sample evaluation, XRD results, and EMP results (when available) to define the major and minor mineral phases present, as well as the overall classification of the rock. Transmitted and reflected PLM provided valuable information on rock and mineral textures that helped to define the existence and sequence of geologic processes that in turn introduced the elements of interest into rocks found on the site and surrounding area.

\subsection{Elemental Analysis and Mineral Identification by Electron Microprobe}

An EMP utilizes a beam of high-energy electrons that can be focused on an area as small as 1 to 2 microns in a sample of solid material. The electron beam, similar to the XRF, displaces electrons from their orbital positions in atoms within the sample, releasing energy in the form of $\mathrm{x}$-rays that is characteristic of a specific element. Figure 3 provides images illustrating the capability of the EMP to enable both mineral identification (using backscattered electrons [BSE]) and elemental composition (using wavelength-dispersive spectroscopy [WDS]).

More than 55 rock and weathered-coating samples were analyzed by EMP for the case study site at University of California, Davis (UCD). The initial EMP evaluation at $\mathrm{UCD}$ identified chromite (containing $\mathrm{Cr}$ ), pentlandite (containing $\mathrm{Ni}$ ), 

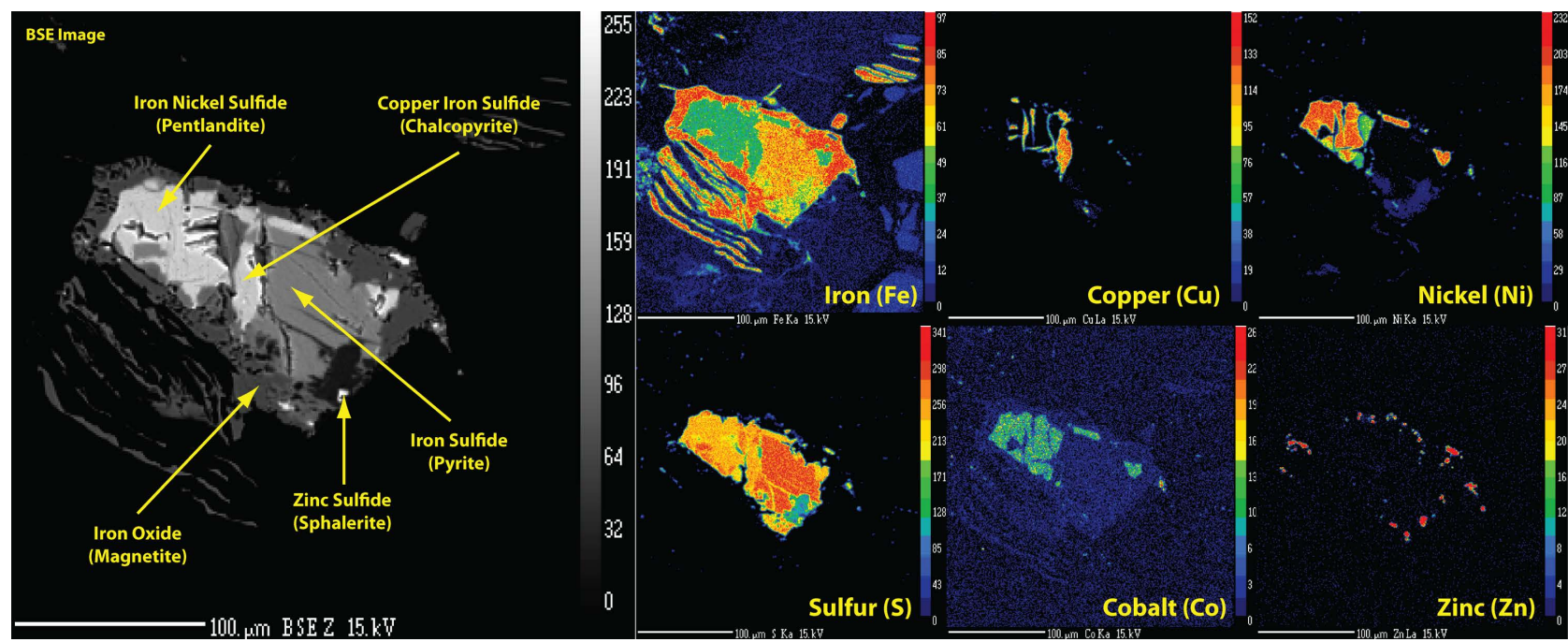

Figure 3. A composite image of several of the analyses performed by the EMP, including a BSE image and several false-color image maps generated by x-ray mapping. At left is a BSE image of a grain containing multiple sulfide minerals, identified by elemental composition and mineral name. At right are false-color element maps for $\mathrm{Fe}, \mathrm{Cu}, \mathrm{Ni}, \mathrm{S}, \mathrm{Co}$ and $\mathrm{Zn}$. Scale bars indicate $100 \mathrm{mi}-$ crons (0.1 millimeter $[\mathrm{mm}])$.

and nickeline (containing both $\mathrm{Ni}$ and As), ore minerals containing three of the elements of interest, in rock samples from the site. These findings resulted in an expanded emphasis on the use of EMP in concert with the PLM, and numerous additional ore minerals were identified using EMP. The EMP results proved very useful in calibrating the observations made using reflected-light PLM. Many of the ore minerals were quantified to provide both definitive concentrations of the elements of interest (in weight percent) and elemental abundance (in atomic percentage) to verify mineral identification using published molecular formulas for the identified minerals.

Duplicate polished thin sections for selected samples from the case study site were analyzed at the California Institute of Technologies (Caltech) using a Scanning Electron Microscope (SEM) equipped with energy-dispersive spectroscopy EDS. The SEM was used to evaluate mineral texture and elemental composition of individual mineral phases using BSE and EDS. Results corroborated findings from UCD, identifying the presence of monazite, a rare earth element (REE) mineral composed of cerium $(\mathrm{Ce})$, lanthanum $(\mathrm{La})$, and neodymium $(\mathrm{Nd})$, among other minerals also identified at UCD.

\section{Case Study}

The case study site is located in the San Gabriel Mountains of southern California and was previously occupied by an industrial facility. Following closure of the facility, environmental assessment and subsequent cleanup activities were performed consistent with applicable U.S. EPA and State of California regulations. As part of a human-health risk assessment and ecological risk assessment, performed consistent with U.S. EPA guidance, anomalous concentrations of As, $\mathrm{Cr}, \mathrm{Ni}$, and other metals and metalloids identified in site soils and weathered 
rocks. These concentrations were initially attributed to anthropogenic sources (e.g., spills and releases at the facility). A human-health risk assessment performed for the site consistent with U.S. EPA guidance identified the presence of As at concentrations resulting in a risk greater than $1 \times 10^{-6}$ via direct exposure, and identified $\mathrm{Cr}$ and $\mathrm{Ni}$ at concentrations resulting in potential health risks via exposure to groundwater. Screening levels were developed to guide the cleanup of the site in order to reduce or remove the identified risks.

Following completion of planned cleanup activities, samples were collected from the sidewalls and floor of the excavation to "confirm" the removal of the target elements by demonstrating that the bedrock remaining after completion of the excavation contained the target elements at concentrations below the screening levels. These confirmation samples from wall rock and underlying bedrock in the excavation revealed concentrations of As, $\mathrm{Cr}$ and Ni significantly higher than screening levels. The case study was therefore designed to evaluate whether the target elements in the bedrock after completion of the excavation were attributable to historic site operations or due to natural processes. Onsite examination of the bedrock and a subsequent literature review revealed that the local area was within a historic mining district and the site was within 1.5 to 2 kilometers $(\mathrm{km})$ of several hard rock mines, suggesting a possible geogenic source of the metals and metalloids. A geochemical study was then designed and implemented to determine the origin of the metals and metalloids present at the site.

\subsection{Regional, Local, and Site Geology}

The San Gabriel Mountains encompass approximately $2500 \mathrm{~km}^{2}$ and are predominated by igneous and metamorphic rocks extensively altered by structural deformation, hydrothermal alteration, and weathering [7]. The igneous rocks cooled and solidified below the earth's surface, and are thus intrusive igneous rocks, including granite, gabbro, and serpentinized peridotite. The metamorphic rocks at the site were originally igneous rocks that were altered by heat and pressure during burial to gneisses (e.g., granitic gneiss) and schists (e.g., tremolite schist). Structural deformation features include folding, local to large-scale faulting, and fracturing, due in large part to the site's location in the San Gabriel Mountains near an active tectonic plate boundary.

A significant portion of the San Gabriel Mountains is enriched in metal elements. Metal element enrichment is due to extensive hydrothermal activity that is responsible for more than one hundred historic lode vein mines located near and in the watershed of the San Gabriel River. Hydrothermal processes include the movement of heated water primarily through fractures and fault zones, with the deposition of quartz and metallic sulfide minerals in veins. Upon exposure near the ground surface, sulfide minerals are especially susceptible to weathering, and metals or other elements can then be concentrated in hydrous Fe oxides (fine, often-powdery, yellow to red material) that form on weathered surfaces and in near-surface fractures. 
The case study involved detailed evaluations of samples collected from both the facility (site) and surrounding areas up to $3 \mathrm{~km}$ distant. Most of the rock exposures throughout the area consisted of granite or granitic gneiss (a metamorphic rock similar in composition to granite), while examination of surface exposures identified only one small outcrop of serpentinite (a metamorphosed ultramafic rock) located at the site. In the subsurface, however, occurrences of serpentinite were noted in abundance in the excavation and in multiple drill cores at the site. Serpentinite is globally one of the most common ultramafic rock types; although at the site some of its occurrences were further metamorphosed (to tremolite-talc schist) or pulverized in faulted zones retrieved from drill core. During transformations such as the formation (by serpentinization of peridotite), metamorphism and weathering of serpentinite, $\mathrm{Cr}$ and $\mathrm{Ni}$ concentrations are relatively unaffected, based on comparisons of unaltered and altered serpentinites from the geochemical study. This relative immobility of $\mathrm{Cr}$ and $\mathrm{Ni}$ in serpentinite is also supported by various studies reported in the literature [8] [9] [10]. Where weathering is intense, $\mathrm{Ni}$ can also accumulate in portions of soils developed on ultramafic bedrock [11]. Many of the confirmation samples consisted of serpentinite, and sample analyses indicated elevated levels of $\mathrm{Cr}$ and $\mathrm{Ni}$. Many of the samples were also observed with coatings of hydrous Fe oxides along fracture and surfaces. Hydrous Fe oxides are highly effective sorbents of many metals and metalloids, and many confirmation samples contained elevated levels of As.

\subsection{Metal and Metalloid Abundance and Origin}

In this section we discuss metal and metalloid distribution, abundance, and origin based on an integration of results from the methods presented in Section 3 and in the Supplementary Information following the references. The general workflow consisted of visual lithologic examination and subsequent petrographic examination using PLM to provide the rock type and primary mineral composition of a specimen, which in turn can indicate the approximate level of metal composition of the specimen. Analytical methods were then employed. Mineralogical identification was confirmed using XRD and EMP. The specific chemical composition of a specimen was obtained through use of XRF, while the composition of specific portions of a sample was obtained using EMP. Because the EMP beam can focus on a small portion of a sample, the EMP was used to confirm mineral identifications of individual mineral grains in a specimen. For definitive evaluation and interpretation of metals and metalloids present in a rock, soil or sediment sample, the best approach is typically a combination of all methods listed above, to build a conclusive case based on multiple lines of evidence. Table 1 lists the ore minerals identified in samples from the case study by one or more of the methods (generally at least two) described in Section 3.

\subsubsection{Stage I-Metals Deposited During Igneous Activity}

Two Cr- and Ni-bearing mineral types were found in ultramafic igneous rock 
samples in fairly high frequency: 1) the spinel-group minerals of Cr-bearing magnetite, and locally, chromite; and 2) the $\mathrm{Ni}$ sulfide mineral pentlandite. In ultramafic rocks from the site and surrounding area, Cr-bearing spinel minerals were observed in nearly every specimen, typically as well-formed, compact octahedral crystals up to $0.25 \mathrm{~mm}$ in diameter. Figure 4 provides an example of well-formed, presumably early-crystallizing spinel grains in an ultramafic rock from the site. Both of the spinel minerals identified at the site (Cr-bearing magnetite and chromite) form by crystallization at high temperatures within the magma [12]. In its pure end-member chemical formula, chromite contains 54\% Cr. Chromite is most commonly found in the lower, ultramafic portions of layered mafic and ultramafic (igneous) intrusions, and is a common accessory mineral in the ultramafic rock peridotite [13]; it is also commonly found in the metamorphic rock serpentinite (derived from metamorphism of ultramafic igneous rocks such as peridotite and dunite). Chromite is one of the two primary ore minerals for $\mathrm{Cr}$.

Table 1. Ore minerals identified in samples from the site and surrounding area.

\begin{tabular}{|c|c|c|}
\hline As-bearing Ore Minerals & Cr-bearing Ore Minerals & Ni-bearing Ore Minerals \\
\hline - Nickeline & - Chromite & - Nickeline \\
\hline - Gersdorffite & - Cr-bearing Magnetite & - Pentlandite \\
\hline - Cobaltite & & - Co-bearing Pentlandite \\
\hline - Arsenopyrite & & - Ni-bearing pyrite \\
\hline \multicolumn{3}{|c|}{ Other Ore Minerals } \\
\hline - Chalcopyrite & - Bornite & - Gold \\
\hline - Sphalerite & - Magnetite & - $\quad$ Silver \\
\hline - Galena & - Rutile & - $\quad$ Barite \\
\hline
\end{tabular}

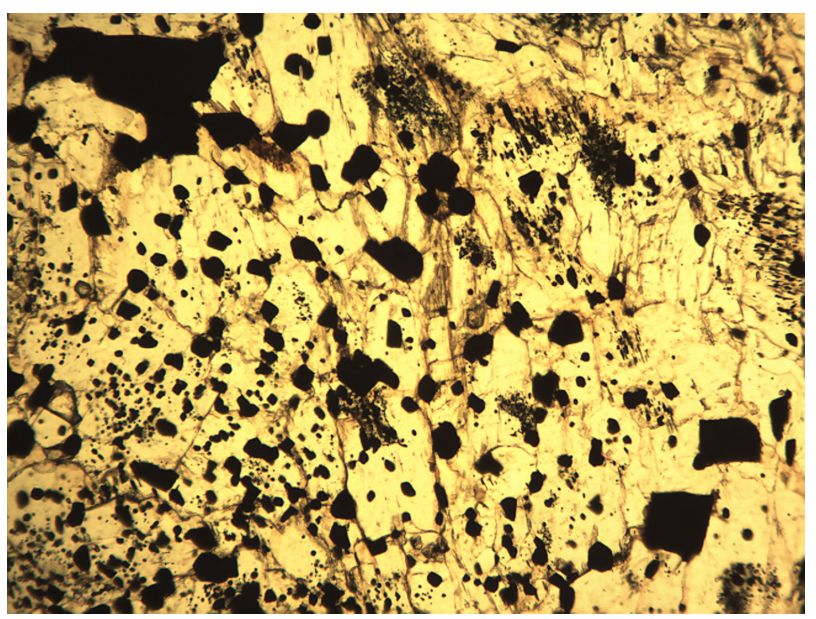

Figure 4. Cr-bearing spinel grains (black) in an ultramafic rock under transmitted light PLM. These relatively coarse, well-formed (euhedral) crystals are likely to have formed from a magmatic liquid, consistent with literature descriptions of their formation as primary (early-formed) minerals in ultramafic igneous rocks. Field of view is $1.2 \mathrm{~mm}$. 
The bulk of $\mathrm{Cr}$ in these Cr-bearing minerals is limited to these mineral grains, as illustrated in Figure 5. The element maps shown in this figure indicate that 1) $\mathrm{Cr}$ is associated with Cr-bearing magnetite, which is an early-formed, high-temperature igneous mineral; and 2) Cr has not been mobilized from the Cr-bearing magnetite mineral grains or deposited in other minerals. These observations, consistent across the case study site, help to ascertain the origin and conditions of formation for this primary Cr-bearing site mineral. These patterns contrast with those of Fe, which is present in other minerals in the sample; furthermore, the veins in this sample (containing $\mathrm{Fe}$ ) represent a later, separate stage of deposition of $\mathrm{Fe}$ than the early spinel.

Pentlandite is an Fe-Ni sulfide mineral that forms at elevated temperatures in ultramafic and mafic igneous rocks. The texture illustrated in Figure 6 of a magnetite rim completely surrounding an oval-shaped grain of sulfide minerals indicates that the sulfides (pentlandite, pyrite, and chalcopyrite) formed earlier than the magnetite rim. Other evidence indicates that this later magnetite rim is chemically and texturally very different from the early-formed Cr-bearing magnetite (it has less $\mathrm{Cr}$ ), and formed later than the magmatic solidification of the ultramafic rock, during metamorphism that converted olivine to serpentine and magnetite (see Section 4.2.2 below).

Pentlandite generally contains slightly more than $34 \%$ weight $\mathrm{Ni}$. It was observed in ultramafic rock samples and in one felsic rock. Cobalt (Co) can also substitute in pentlandite's mineral structure. Figure 3 (in Section 3 ) shows a typical occurrence of pentlandite, with chemical concentrations from EMP analysis in false-color. The left central portion of the large grain contains significant $\mathrm{Ni}, \mathrm{Fe}$, and $\mathrm{S}$ concentrations that indicate the presence of the mineral pentlandite. In addition, $\mathrm{Co}$, while at a lower concentration than $\mathrm{Ni}$ and $\mathrm{Fe}$, almost perfectly follows the distribution of $\mathrm{Ni}$, thus illustrating that the mineral is a

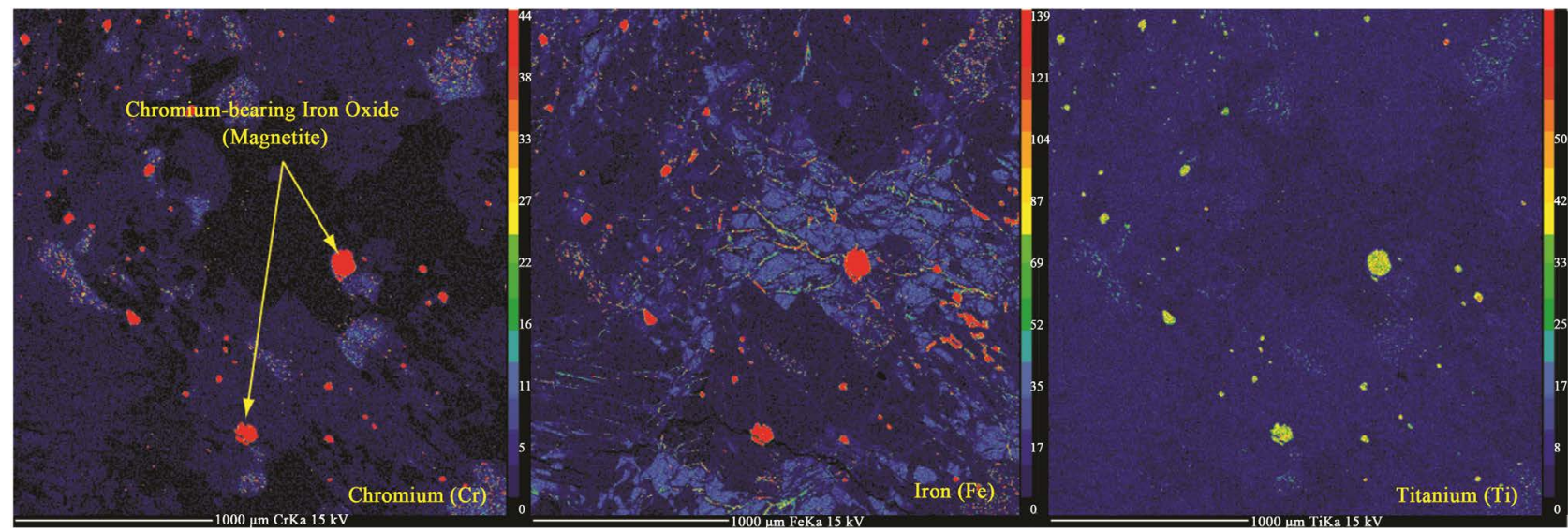

Figure 5. Spinel grains in false-color element maps (higher concentrations in warm colors) from the EMP showing concentrations of $\mathrm{Cr}$, along with $\mathrm{Fe}$ and titanium (Ti), elements that are commonly present in spinel minerals, in this case Cr-bearing magnetite. The highest concentrations of $\mathrm{Cr}$ in this sample (in red) are limited to the compact zones of Cr-bearing magnetite. Fe and $\mathrm{Ti}$ are also found in these same zones ( $\mathrm{Ti}$ is a minor element in $\mathrm{Cr}$-bearing magnetite and thus shows up in green). However, note that Fe is also present in other areas, especially as wavy veinlets, probably in the form of magnetite. Scale bars $=1 \mathrm{~mm}$. 


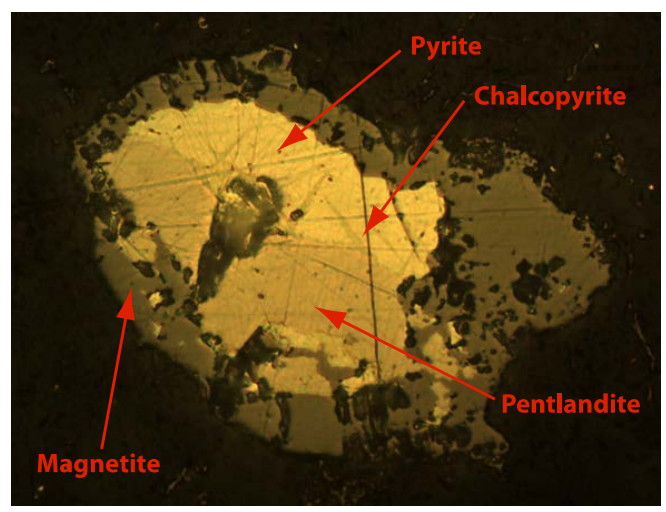

Figure 6. Oval sulfide grain with a magnetite rim, in ultramafic rock, by reflected light PLM. Magnetite forms a complete rim around the sulfide minerals pentlandite and pyrite, and thus was introduced later than the sulfides. Field of view is $0.3 \mathrm{~mm}$.

Co-bearing variety of pentlandite. The right central portion of this grain contains significant $\mathrm{Fe}$ and $\mathrm{S}$ concentrations, which indicate the presence of pyrite. Between the two mineral phases described above, there is a zone containing significant $\mathrm{Cu}, \mathrm{Fe}$, and $\mathrm{S}$ concentrations, which indicate the presence of the mineral chalcopyrite. The outer symmetrical rim (mostly in orange in the Fe image) primarily contains $\mathrm{Fe}$ without $\mathrm{S}$, and thus represents Fe oxide (similar to the example in Figure 6). The specific Fe oxide of the symmetrical rim is likely magnetite based on the geological and mineralogical settings, because similar textures are present in other rocks from the site and adjacent areas. Also, none of the other mapped elements are present in this outer rim.

The minerals pentlandite and Co-bearing pentlandite are metal sulfide minerals that have been hypothesized to most commonly originate by crystallization within metal and S-rich segregations, usually within the lower portions of a mafic or ultramafic magma. During cooling of the magma, the metal plus $S$ zones congregate and form a monosulfide solid solution (MSS). When the MSS cools below about $575^{\circ} \mathrm{C}$, it separates (exsolves) into metal sulfide minerals [13] [14]. Pentlandite and Co-bearing pentlandite are present in samples with other MSS-related minerals such as pyrrhotite, pyrite, and chalcopyrite, suggesting their collective origin as high-temperature minerals formed in association with the magma.

\subsubsection{Stage II. Metamorphism}

Most site rocks show evidence of metamorphism. Ultramafic rocks in particular show extensive metamorphic features in nearly all specimens. An example is shown in Figure 7, which illustrates three metamorphic minerals in an ultramafic rock. Two of these, magnetite and serpentine, are often closely associated in small veins traversing the mineral olivine. Tremolite is generally formed at temperatures above $400^{\circ} \mathrm{C}$ [14]. It was formed after serpentine and magnetite had formed, because it contains many small, parallel laminations of magnetite (dark zones in the upper left of Figure 7; also see the upper right part of Figure 4 , showing many fine lamellae of magnetite). 
The magnetite that was metamorphically generated during serpentinization of ultramafic rocks also formed rims around sulfide grains, as shown in Figure 8. These rims, very commonly observed under the PLM and EMP (see also Figures 3-6), allowed us to confine the period of deposition of the Stage I metal sulfides in the interior of such rimmed grains to a time earlier than the metamorphism. This means the metals in the sulfide zones have been relatively isolated from the surrounding environment for an extended period; thus they could not have been anthropogenically generated, and must have been geogenic.

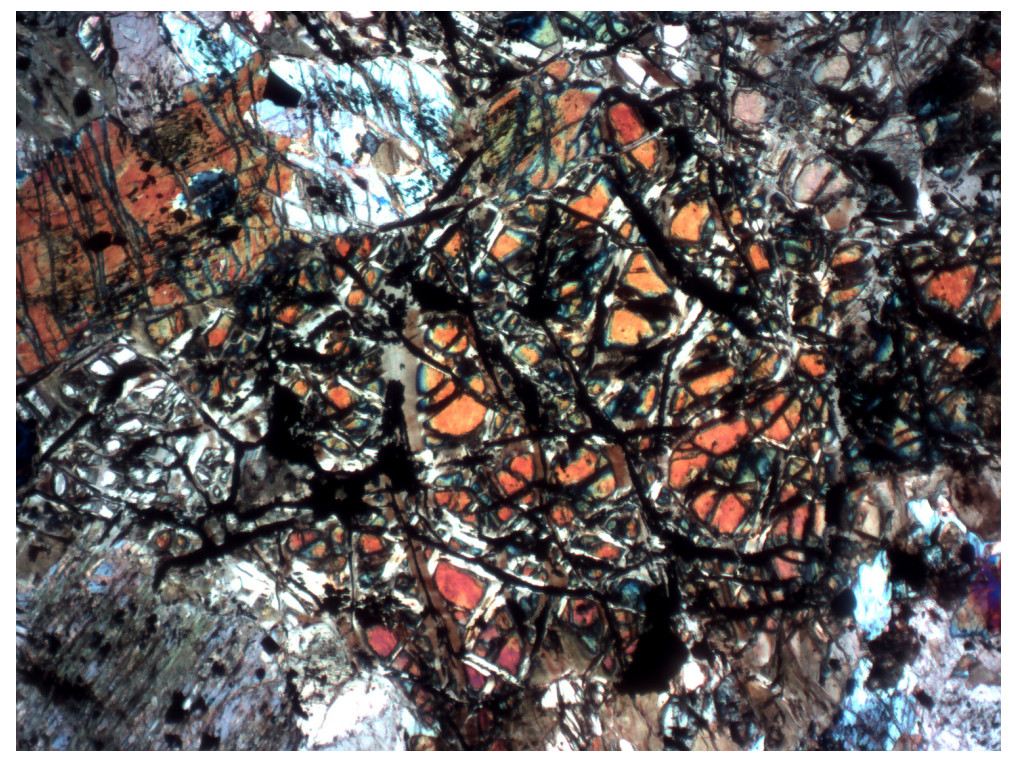

Figure 7. A photomicrograph of an ultramafic rock under transmitted light PLM showing a partly serpentinized olivine grain (at center, in orange), altered along fractures to magnetite (black veins) and serpentine (white to light gray zones adjoining magnetite). The serpentine and magnetite were thus formed later than the olivine. Tremolite (large orange and white grain at upper left) with fine magnetite (very fine black crystals and lamellae), also metamorphic products, are at upper left.

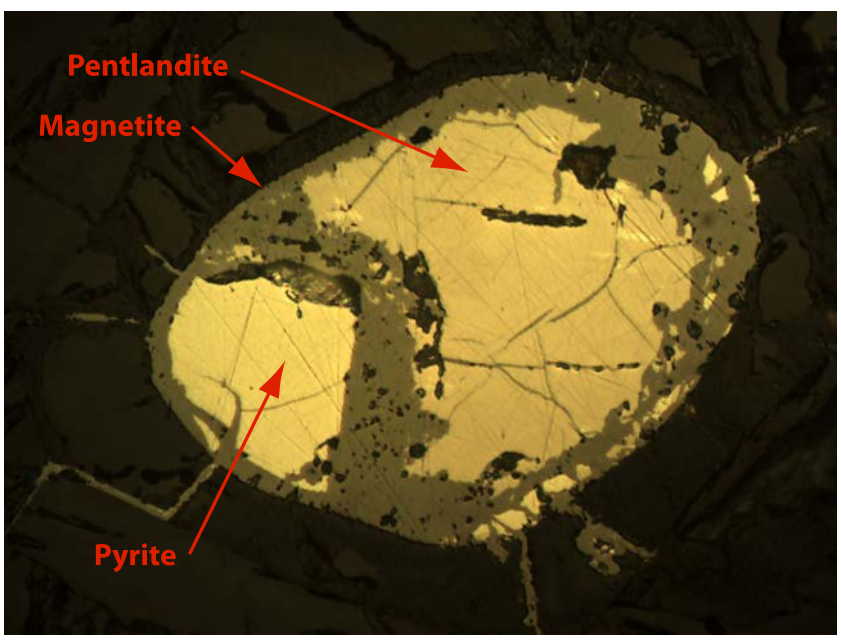

Figure 8. Magnetite rim around the sulfide minerals pyrite and pentlandite in another oval-shaped grain under reflected light PLM. Field of view $0.3 \mathrm{~mm}$. 


\subsubsection{Stage III. Metals Deposited During Hydrothermal Activity}

Textures visible in petrographic thin sections indicate that a period of hydrothermal activity affected rocks at the site, and additional metals along with metalloids were deposited. Another example of the texture where minerals form rims around other mineral grains is shown in Figure 9.

Two other examples of hydrothermal deposition of metals and metalloids are shown in the illustrations of Figure 10. Textures in this slide support a sequence of events, with the hydrothermal minerals (metal sulfides) filling in spaces between the metamorphic minerals, and in fractures that cut the metamorphic minerals. Both textures indicate that the hydrothermal metal-depositing activity likely occurred after metamorphism.

Hydrothermal activity is supported as a factor in introducing the metals $\mathrm{Ba}$, $\mathrm{Cu}$ (although some $\mathrm{Cu}$ was magmatic, along with most $\mathrm{Cr}$ and $\mathrm{Ni}$ ), $\mathrm{Pb}$ and $\mathrm{Zn}$, the metalloids $\mathrm{As}$ and $\mathrm{Sb}$, and perhaps also accounts for the rare occurrences of gold $(\mathrm{Au})$ at the site. This hypothesis is supported by the fact that the minerals containing these metals and metalloids are generally characterized as hydrothermal minerals that require both elevated temperatures (at least $50^{\circ} \mathrm{C}$, and primarily greater than $100^{\circ} \mathrm{C}$ ) and chemically reducing conditions to form [13].

Supporting evidence for hydrothermal activity is seen in thin sections that host minerals that commonly form through hydrothermal alteration, such as chlorite (a hydrous magnesium $[\mathrm{Mg}]-\mathrm{Fe}$ aluminosilicate) and quartz (silicon dioxide $\left.\left[\mathrm{SiO}_{2}\right]\right)$. For example, Figure 11 shows a thin section of an altered

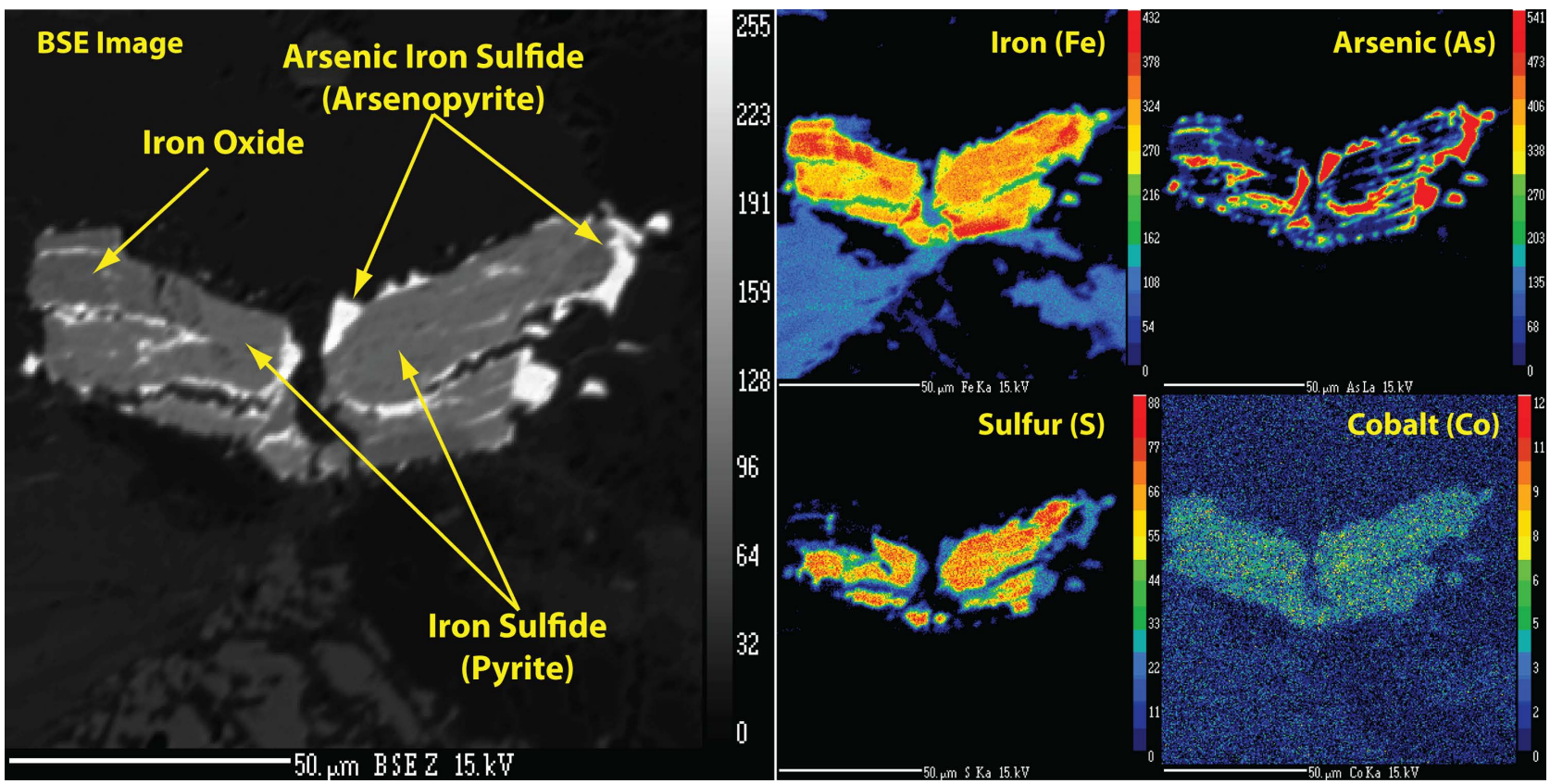

Figure 9. Composite of images from EMP showing effects of hydrothermal alteration. The color images in this figure are again false-color element maps, while the left-hand image shows a BSE image (correlates with density). The outer margins of the BSE image show white areas that were developed as a partial alteration rim around two central grains. The white areas in the BSE image indicate a high-density phase that is arsenopyrite based on its composition (Fe-As sulfide), corresponding to the locations in red in the As element map (right), and moderate levels of Fe and S. The core of the grain is pyrite (composed mainly of Fe and S), and the upper left corner of the grain is an Fe oxide (containing iron with no appreciable S). 


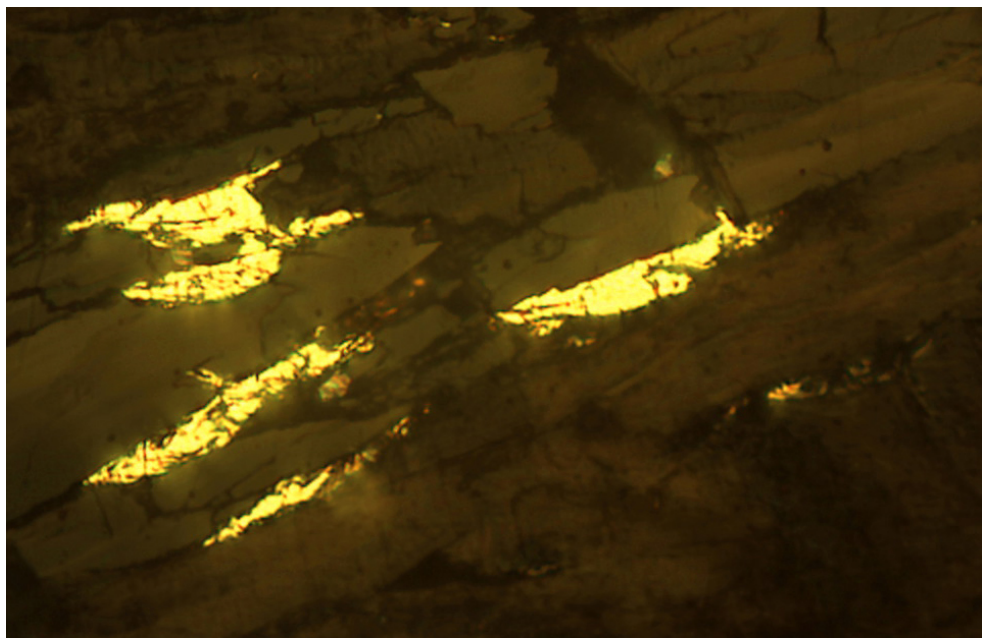

Figure 10. Example of hydrothermal deposition of sulfides. The sulfide mineral chalcopyrite (in yellow) fills in fractures that cut the metamorphic minerals tremolite and talc.

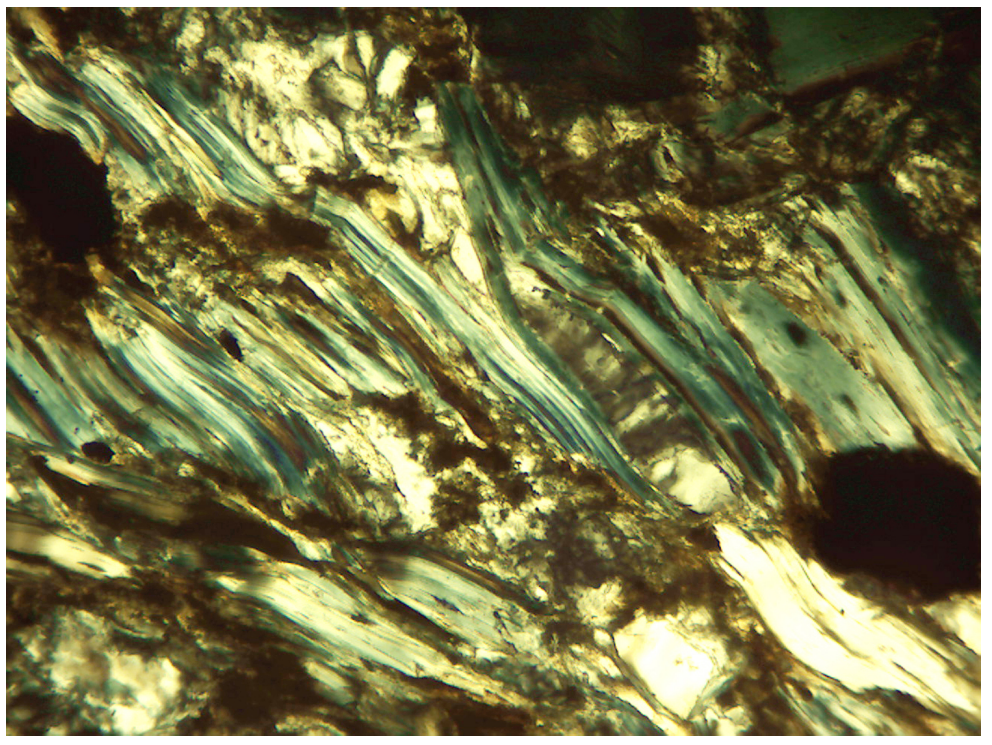

Figure 11. Hydrothermally altered ultramafic rock by transmitted light PLM. Chlorite is the bluish to greenish gray mineral, mostly foliated, while quartz makes up most of the white zones. Most of this slide consists of these two common hydrothermal minerals. Field of view $1.2 \mathrm{~mm}$.

ultramafic rock that consists primarily of these two minerals. Because in unaltered form they are low in $\mathrm{SiO}_{2}$, ultramafic rocks generally do not contain more than trace amounts of quartz, unless $\mathrm{SiO}_{2}$ has been introduced to the rock during hydrothermal alteration (metasomatism). The petrographic identification of chlorite and quartz was corroborated using the benchtop XRD instrument, with the quantitation showing that about $70 \%$ of this specimen consists of quartz and chlorite (variety clinochlore). The high amount of $\mathrm{Si}$ (in quartz) in this altered ultramafic rock confirms the idea of element transfer into the specimen (metasomatism). Furthermore, the XRF data for this specimen documents that other elements are at concentrations much higher than those typical of unaltered ul- 
tramafic rocks (As at $1200 \mathrm{mg} / \mathrm{kg}$, as well as elevated proportions of $\mathrm{Cu}, \mathrm{Pb}, \mathrm{Sb}$, and $\mathrm{Zn}$ ), supporting the metasomatism of those elements as well into this altered specimen. In unaltered ultramafic and granitic rocks globally, average As concentrations are much lower, at $1.5 \mathrm{mg} / \mathrm{kg}$ in both [15].

The variety of the arsenide and sulfide minerals observed in moderate abundance at the site indicate hydrothermal deposition, including arsenopyrite, barite, chalcopyrite, galena, gersdorffite, nickeline, and sphalerite. Except for chalcopyrite and possibly gersdorffite, all these minerals are known almost exclusively as hydrothermal phases [13]. Chalcopyrite is known from a wide variety of geologic environments, including both magmatic and hydrothermal. The overall suite of these coexisting minerals supports hydrothermal activity for their origin. This idea is further supported by the existence of at least one mine within $1.5 \mathrm{~km}$ of the site, and the presence of multiple mining districts in the San Gabriel Mountains, including hydrothermal precious-metal districts. Also, As has been estimated to be present at one to three orders of magnitude greater in waters of geothermal and hydrothermal systems than in unimpacted cold groundwaters [16]. Other researchers [17] [18] [19] have noted elevated As in waters and minerals at hydrothermal systems, and hypothesized that As can be a good indicator element (as part of a suite of indicator elements [20]) for prospecting for precious metal and other hydrothermal deposits.

Similar to the arsenopyrite example in Figure 9, the Zn sulfide mineral sphalerite can be observed in the outer portions of compound grains, such as in Figure 3. This figure was presented above, but observes the $\mathrm{Zn}$ element map of this figure showing how $\mathrm{Zn}$ is located exterior to where the other metals are located in the grain; $\mathrm{Zn}$ also coincides with occurrences of $\mathrm{S}$ in these locations. This distribution, in the outer, more-accessible portions of the grain, suggests that $\mathrm{Zn}$ was deposited later than $\mathrm{Cu}, \mathrm{Fe}$, and $\mathrm{Ni}$ - the latter metals represent igneous deposition early in the site's geologic history. The $\mathrm{Zn}$ is thus another example of a later phase of hydrothermal deposition of metals at the site.

\subsubsection{Stage IV. Metals Deposited During Weathering}

Weathering is an important process at the case study site. The San Gabriel Mountains were uplifted fairly recently geologically, and the area has been subject to extensive movement along a plate-boundary set of faults. This large-scale movement created significant strains, resulting in abundant fractures visible in rock exposures near the site, and created relatively open pathways for infiltrating precipitation. Sulfide and arsenide minerals, containing $S$ and As in reduced forms, are especially susceptible to oxidative chemical weathering. When decomposing, these minerals tend to release ionic $S$, which under oxidizing conditions leads to the formation of sulfuric acid. The acid facilitates chemical weathering additional to that caused by water and carbonic acid in precipitation. As a result, areas near sulfide mineral concentrations (i.e., mines and less valuable concentrations) tend to experience moderate to extensive mineral leaching caused by reactions involving sulfuric acid. 
In the site excavation, bedrock was observed to be highly fractured and weathered, especially along fractures, at the ground surface and extending to the bottom of the excavation $(9 \mathrm{~m})$; in drilling cores, fracturing and some weathering were observed to depths of at least 10 to $20 \mathrm{~m}$. Groundwater is at least $18 \mathrm{~m}$ deep at all locations drilled, with the result that the upper $18 \mathrm{~m}$ of the subsurface are within the vadose zone and are thus oxygen-rich; accordingly, sulfides at these depths are unstable chemically. Chemical weathering of site rocks and minerals is thus fostered by the combination of the relatively unstable sulfide and arsenide minerals; the warm (Mediterranean-type) climate with seasonally intense precipitation; open fracturing of bedrock; and a thick vadose zone.

Sulfide and arsenide minerals exposed to chemical weathering tend to break down along mineral grain margins and along fractures. This decomposition leads to the formation of fine-grained, oxidized minerals, such as the Fe oxides goethite and hematite, other Fe oxide minerals, and manganese (Mn) oxides. The metal constituents in the former sulfide and arsenide minerals are liberated from the crystal structure through decomposition and are available for transport in near-surface runoff or percolation waters according to their respective solubilities under oxidizing conditions. Some metals and metalloids present at the site, particularly $\mathrm{As}, \mathrm{Cu}, \mathrm{Pb}, \mathrm{Ni}$, and $\mathrm{Zn}$, are very susceptible to sorption to hydrous Fe oxide minerals such as goethite [20] [21]. This phenomenon accounts for the concentrations of these elements in yellowish brown to orange-brown mineral coatings and fracture-fillings commonly observed on exposed surfaces at the site. Figure 12 is an XRD pattern that documents the abundant presence of oxidized and hydrous minerals in a weathered sample, including hydrous Fe oxides (goethite, ferrihydrite) and clay minerals (kaolinite, montmorillonite), as well as chemically resistant minerals (quartz, lizardite [serpentine], arsenopyrite).

Some of the weathered coatings were thick enough (several $\mathrm{mm}$ ) that they constituted a significant volumetric proportion of samples collected from the walls of the facility excavation, which were in a heavily weathered location as deep as $9 \mathrm{~m}$ below ground. Samples of the coatings were collected on site, as well as directly uphill from the site, to evaluate the prospect of chemical weathering producing elevated metal levels independent of site contribution. To examine these possibilities, segregated samples of the oxidized coatings were collected by chipping and abrasion, and grain mounts of this weathered surficial material were prepared, as described in the supplemental information.

Grain mounts of segregated weathered material provided evidence that metals had a similar abundance and character throughout the local area. Some examples are presented below. One such area where coatings were sampled, as well as the surrounding host rock, is shown in Figure 13. The As concentration in the segregated sample of the weathered material from this location was $656 \mathrm{mg} / \mathrm{kg}$, while the whole-rock sample contained $49.5 \mathrm{mg} / \mathrm{kg}$ As (both results obtained with the benchtop XRF instrument). Concentrations of $\mathrm{Cu}, \mathrm{Pb}, \mathrm{Ni}$ and $\mathrm{Zn}$ were 


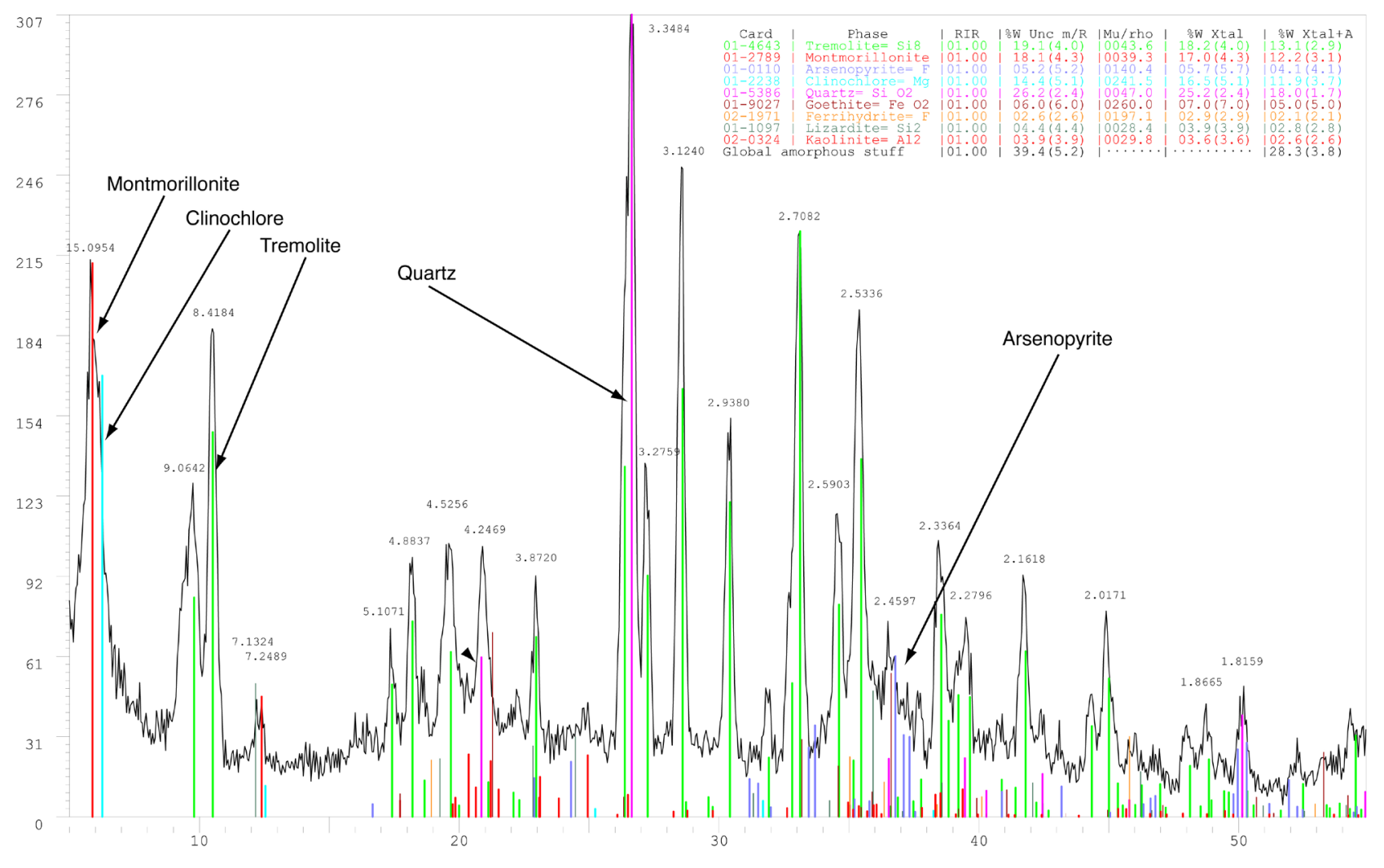

Figure 12. X-ray diffraction pattern of a weathered coating, with representative peaks labeled for the relatively abundant minerals.

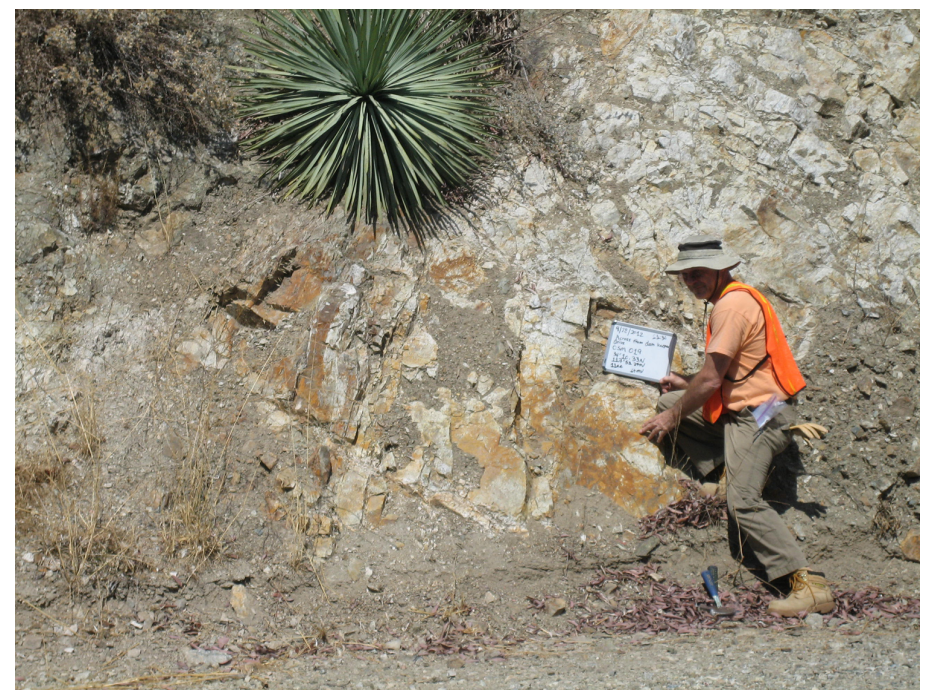

Figure 13. Geologist examining weathered rock along a road cut uphill from the site. The orange-brown material on the exposed surface consists mainly of $\mathrm{Fe}$ oxides (some are likely hydrous), while the lithology of the main body of the exposure is felsic igneous rock.

similarly higher by about one order of magnitude in the oxidized material compared to the whole-rock sample. Similar magnitudes of enrichment in weathered surfaces (and fracture fillings) relative to whole-rock samples were observed at many locations. 
Figure 14 shows how sulfide minerals are corroded by chemical weathering to form hydrous iron oxides, starting from the outside of the mineral grain. This type of weathering was found at many case study sample locations, both onsite and offsite.

Figure 15 is a false-color element map from the EMP of a grain-mount sample of a segregated sample of weathered material. This figure shows the close association of As with Fe.

Metals and metalloids liberated from the weathering of sulfide and arsenide minerals were likely sorbed to hydrous Fe oxides, as illustrated for As on Figure 15. The locally thick coatings along fractures and exposed surfaces, rich in hydrous Fe oxides, are also rich in $\mathrm{Cr}, \mathrm{Ni}$, and other metals. This is illustrated in Figure 16, which presents a set of bar charts showing concentrations of As, Cr, and $\mathrm{Ni}$ in felsic rocks, as a function of the general level of weathering; the highest degree of enrichment is clearly in the category "weathered coatings," which

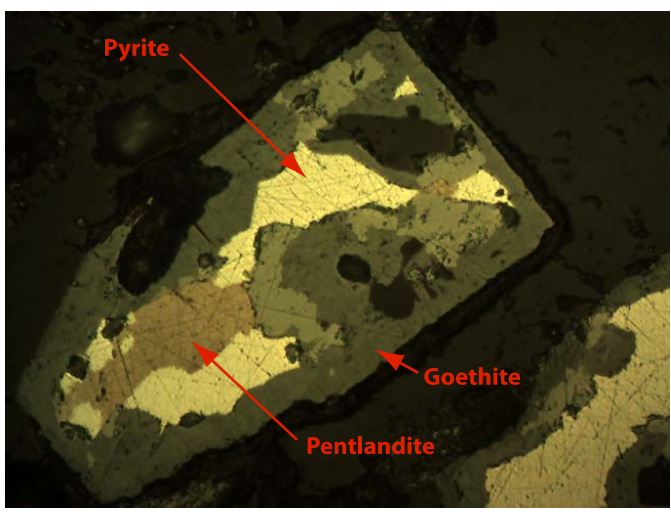

Figure 14. Sulfide minerals pyrite and pentlandite corroded by chemical weathering, under PLM. The medium to dark gray materials along the outer rims of this sample are Fe oxides, the dark gray likely being the hydrous mineral goethite. The Fe oxides appear to have pseudomorphically replaced the sulfides from the outside in, such that the original crystal form is retained. Field of view is $0.3 \mathrm{~mm}$.
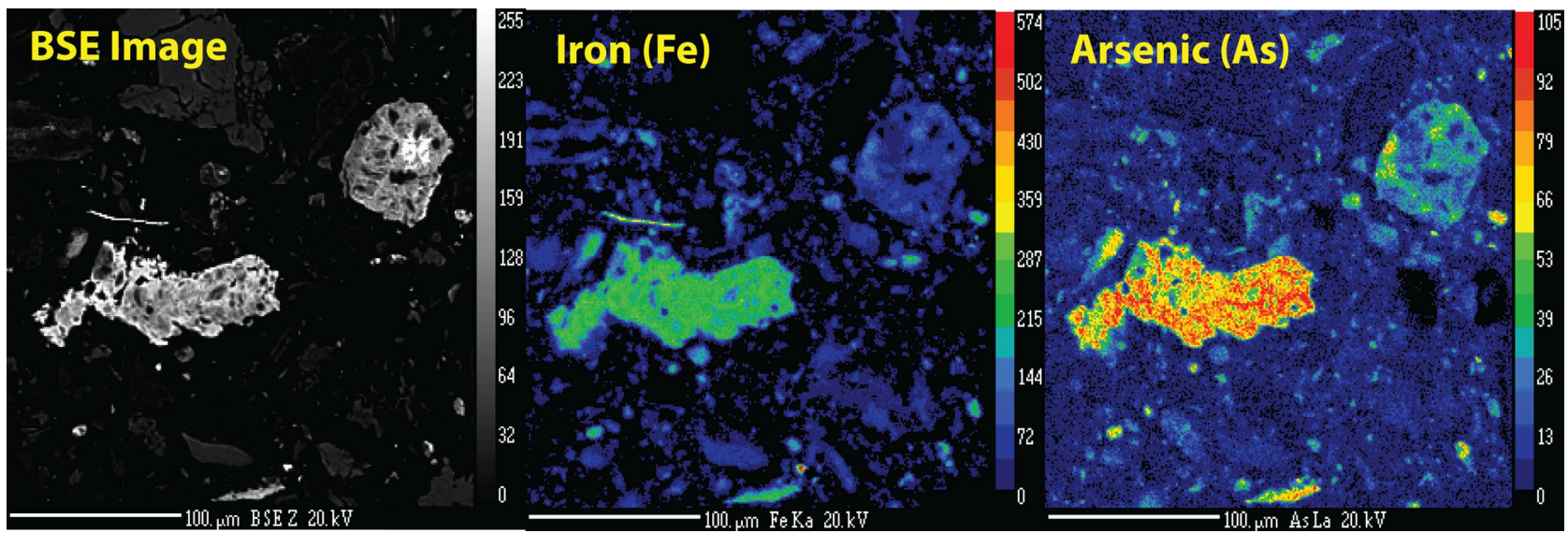

Figure 15. BSE and false-color images of a segregated sample of weathered material. There is substantial As in many separate grains of this sample, and most of these grains also have elevated levels of Fe (note that the color-scales for the elements are relative; in all cases $\mathrm{Fe}$ is present in greater concentrations than As). Scale bar is 100 microns $(0.1 \mathrm{~mm})$. 

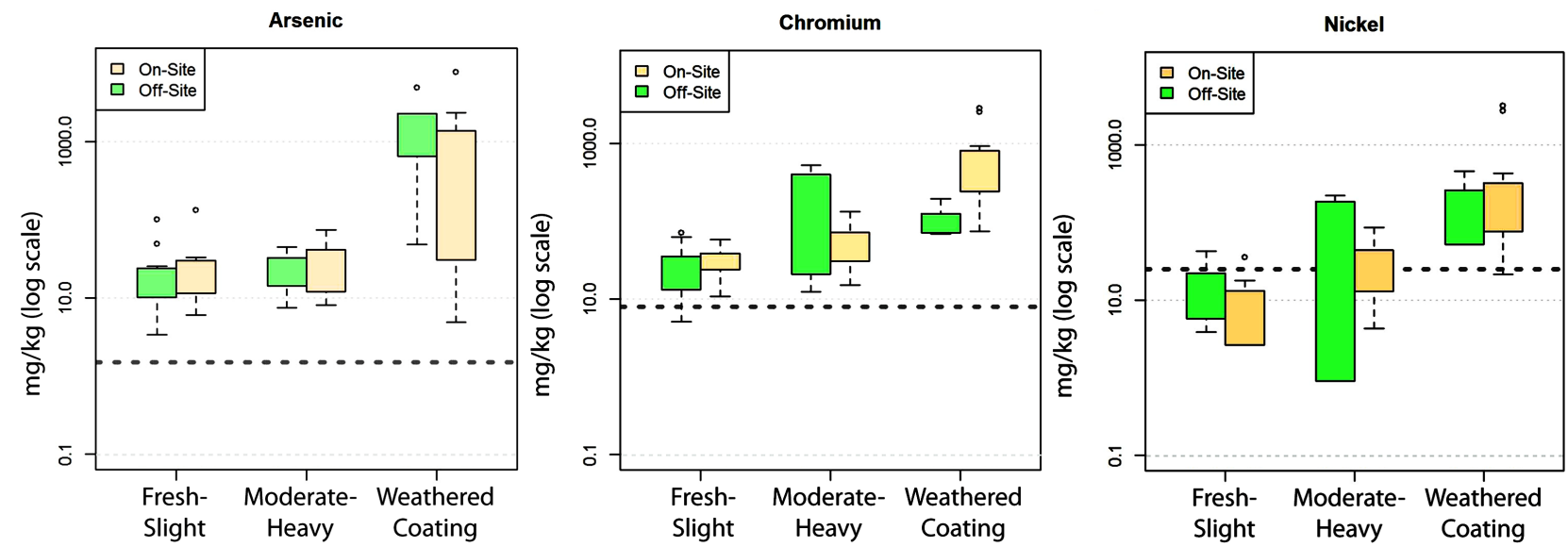

Figure 16. Concentrations of $\mathrm{As}, \mathrm{Cr}$, and $\mathrm{Ni}$ in felsic rocks, according to the general level of weathering (along the $\mathrm{x}$-axis). Also, on-site rocks (beige bars) are distinguished from off-site rocks (green bars). In each plot, the weathering category at the right is "weathered coatings," which refers to the mineral material on exposed surfaces (segregated from the host rock for sampling) that commonly ranges from yellow-brown through orange-brown to black. It is apparent that, proceeding from fresh-slightly weathered samples to moderately-heavily weathered samples, As is slightly enriched. However, proceeding to weathered coatings, As is enriched by at least an order of magnitude. Peak values for As in felsic rocks ranged up to 7,880 $\mathrm{mg} / \mathrm{kg}$ in one weathered coating, alongside the corresponding whole-rock sample that contained $133 \mathrm{mg} / \mathrm{kg}$ As. Patterns for $\mathrm{Cr}$ and Ni are generally similar to patterns for As, but without the same degree of enrichment in the weathered coatings category. Though not illustrated here, patterns for weathered coatings in ultramafic rocks were similar (though not as enriched) as those displayed here for felsic rocks.

refers to the mineral material on exposed surfaces that commonly ranges from yellow-brown through orange-brown to black (i.e., rich in hydrous iron oxides). Though not illustrated here, patterns for weathered coatings in ultramafic rock were similar (though not as enriched) as those displayed for felsic rocks in Figure 16.

Also, some metals and metalloids accumulated in the body of highly weathered rocks rather than being restricted to fractures or surfaces. An example of the sequence of effects of weathering is shown in Figure 17. The increase of As with weathering and oxidation is consistent with significant degrees of sorption of As to hydrous Fe oxides.

Overall, in highly altered ultramafic rocks, median concentrations of $\mathrm{As}, \mathrm{Cu}$, $\mathrm{Mn}, \mathrm{Pb}, \mathrm{Sb}$, and $\mathrm{Zn}$ were higher than in relatively unaltered ultramafic rocks, by factors ranging from 2.6 to 10.7 (see Table 2). (For the "Altered" category, this table combines rocks that display either hydrothermal alteration or moderate-heavy weathering, because in many cases it was difficult to separate these two effects. Because most of the samples were collected from the vadose zone, most samples were at least partly weathered.) In the case of $\mathrm{Cr}, \mathrm{Fe}$, and $\mathrm{Ni}$, median concentrations in highly altered ultramafic rocks were roughly similar to those in relatively unaltered rocks. This contrast is due to the fact that these three metals are already at a high abundance in unaltered ultramafic rocks. In the case of Fe, the critical difference between these two groups is that the oxidation state of $\mathrm{Fe}$ changes from generally reduced $\left(\mathrm{Fe}^{2+}\right)$ to generally oxidized $\left(\mathrm{Fe}^{3+}\right)$ in the highly altered ultramafics, creating Fe minerals (hydrous Fe oxides) with much higher capacity for sorption of metals and metalloids. 


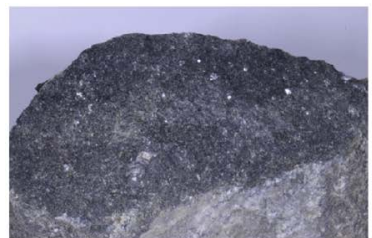

Slightly weathered As $=15.1 \mathrm{mg} / \mathrm{kg}$

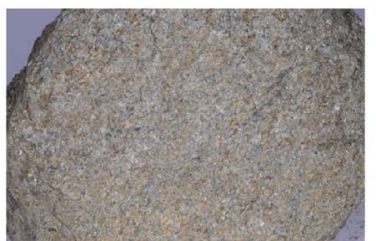

Moderately weathered As $=30.9 \mathrm{mg} / \mathrm{kg}$

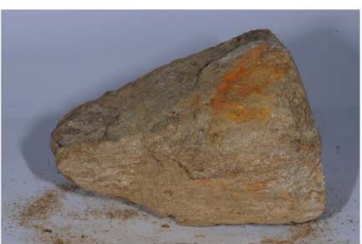

Heavily weathered As $=284 \mathrm{mg} / \mathrm{kg}$

Figure 17. As values for differing degrees of weathering for three ultramafic rocks. Three ultramafic rocks are shown here, ranging from slightly weathered to heavily weathered. In the unweathered rock pictured on the left, Fe-bearing minerals are present in reduced $\left(\mathrm{Fe}^{2+}\right)$ state, forming minerals with dark gray to black color. In the highly weathered rock on the right, fairly high proportions of minerals with oxidized $\left(\mathrm{Fe}^{3+}\right)$ iron account for the orange-brown colors typical of hydrous Fe oxides. A whole-rock analysis of the unweathered rock on the left yielded $15.1 \mathrm{mg} / \mathrm{kg}$ As, while the weathered specimen at the right contained $284 \mathrm{mg} / \mathrm{kg}$ (both measured using the benchtop XRF). The much higher As in the oxidized specimen at the right is consistent with significant degrees of sorption of As to hydrous Fe oxides.

Table 2. Median values for relatively unaltered and highly altered Ultramafic and Felsic rocks (in $\mathrm{mg} / \mathrm{kg}$ ).

\begin{tabular}{cccccccccc}
\hline \multirow{2}{*}{ Rock Type } & \multicolumn{7}{c}{ Elements } \\
\cline { 2 - 9 } & As & $\mathrm{Cr}$ & $\mathrm{Cu}$ & $\mathrm{Fe}$ & $\mathrm{Mn}$ & $\mathrm{Ni}$ & $\mathrm{Pb}$ & $\mathrm{Sb}$ & $\mathrm{Zn}$ \\
\hline Unaltered Ultramafics & 13.0 & 2280 & 25.2 & 76,000 & 1130 & 1080 & 4.55 & 7.67 & $\mathbf{7 4 . 5}$ \\
Altered Ultramafics & $\mathbf{1 3 9}$ & 2360 & 113 & 133,000 & 4390 & 1010 & $\mathbf{3 8 . 5}$ & 23.4 & 197 \\
Unaltered Felsics & 18.5 & 30.0 & 29.0 & 20,200 & 266 & 10.7 & 8.00 & 9.67 & 53.0 \\
Altered Felsics & $\mathbf{2 4 4}$ & $\mathbf{1 5 2}$ & $\mathbf{2 5 0}$ & $\mathbf{2 2 3 , 0 0 0}$ & $\mathbf{3 0 6 0}$ & $\mathbf{1 0 7}$ & $\mathbf{5 9 . 7}$ & $\mathbf{3 0 . 4}$ & $\mathbf{2 9 9}$ \\
\hline
\end{tabular}

Note: Enrichments of greater than $5 \mathrm{x}$ in altered rocks compared to unaltered rocks of the same type are shown in bold.

In felsic rocks, median values of all listed metals and metalloids are distinctly higher in highly altered rocks compared to concentrations in relatively unaltered felsic rocks (Table 2), with enrichment factors ranging from 3.1 to 13.7. Again, similar to the pattern for ultramafic rocks, the highest enrichment factor in felsic rocks was for As.

The element plots and observations discussed above for weathered rocks and coatings support the idea of metasomatism or mass transfer of metals and metalloids to the weathered material present along many fractured surfaces and, to a lesser extent, into the body of weathered rock. There are several independent pieces of evidence consistent with the idea that the origin of these metals in highly altered rocks is geogenic rather than due to anthropogenic activities at the site facilities:

- Enrichment of metals and metalloids involves at least nine elements, several of which are very unlikely to have been used at the site.

- Enrichment of metals and metalloids was observed to similar degrees in offsite rocks compared to onsite rocks (see Figure 16). This includes samples that could not have site-attributable impacts, being from locations notably higher in elevation and/or distant from the site (field samples were collected 
up to $1.5 \mathrm{~km}$ away, from similar rock types as at the site).

- Many of the highly altered samples contain traces or major proportions of minerals that form at high temperatures (most of these minerals typically form at significantly greater than $100^{\circ} \mathrm{C}$ ) and low redox conditions (containing sulfides and arsenides, in which the oxidation states of $S$ and As range from -2 to +1 ). Such conditions would not have prevailed at near-surface depths and temperatures that would have prevailed when the site facilities were in operation.

\subsection{Conceptual Site Model Refinement}

The CSM was refined with information gathered from the geochemical study at the site. This study revealed several lines of evidence supporting the elevated levels of $\mathrm{As}, \mathrm{Cr}, \mathrm{Ni}$ and other metals and metalloids in confirmation samples as geogenic, from a combination of local geologic conditions and regional mineralization. The lines of evidence are illustrated in Figure 18 and summarized below.

- Stage I: Cr-rich minerals (Cr-bearing magnetite and chromite) are associated with the ultramafic rocks observed at the site. These $\mathrm{Cr}$ minerals typically crystallize directly from a magma, and their oxide form renders them relatively stable throughout their post-formation history. Cr-rich minerals occur in magmatic segregations within the locally abundant ultramafic rock. Ni-rich sulfides are also associated with ultramafic rocks observed at the site. The sulfides crystallized in metal and S-rich segregations within the lower portions of ultramafic magma, with magmatic segregation of the immiscible sulfides to form pentlandite (often with Co), pyrite, and chalcopyrite within the melt, with subsequent hydrothermal alteration (see Stage III) of Ni-rich sulfides to form As-rich minerals nickeline and gersdorffite.

\begin{tabular}{|c|c|c|c|c|}
\hline Stage of Mineral Formation & $\begin{array}{l}\text { I - Magmatic Segregations } \\
\text { in Ultramafic Rock }\end{array}$ & II - Metamorphism & $\begin{array}{c}\text { III - Hydrothermal Alteration } \\
\text { and Mineralization }\end{array}$ & IV - Weathered Coatings \\
\hline Minerals formed & $\begin{array}{c}\text { Cr-bearing magnetite, } \\
\text { chromite, pyrite, pentlandite, } \\
\text { chalcopyrite }\end{array}$ & $\begin{array}{l}\text { Serpentine, magnetite, } \\
\text { tremolite, talc }\end{array}$ & $\begin{array}{l}\text { Chlorite, quartz, epidote, } \\
\text { albite; sulfides: chalcopyrite, } \\
\text { galena, sphalerite; arsenides: } \\
\text { arsenopyrite, gersdorffite, } \\
\text { nickeline; sulfates: barite }\end{array}$ & $\begin{array}{c}\text { Hydrous } \mathrm{Fe} \text { oxides and } \mathrm{Mn} \\
\text { oxides; clay minerals; } \\
\text { chrysocolla (hydrous } \mathrm{Cu} \mathrm{Al-} \\
\text { silicate); cerussite ( } \mathrm{Pb} \\
\text { carbonate) }\end{array}$ \\
\hline $\begin{array}{c}\text { Elements Deposited or } \\
\text { Remobilized }\end{array}$ & $\mathrm{Cr}, \mathrm{Fe}, \mathrm{Ni}, \mathrm{Cu},(\mathrm{Co})$ & $\begin{array}{l}\text { (Fe) (remobilized, not } \\
\text { introduced) }\end{array}$ & $\begin{array}{c}\mathrm{As}, \mathrm{Ba}, \mathrm{Cu}, \mathrm{Fe}, \mathrm{Mn},(\mathrm{Ni}) \\
\mathrm{Pb}, \mathrm{S}, \mathrm{Zn}\end{array}$ & $\begin{array}{c}\mathrm{As}, \mathrm{Ba},(\mathrm{Cr}), \mathrm{Cu}, \mathrm{Fe}, \mathrm{Mn} \\
\text { Ni, Pb, Sb, Zn }\end{array}$ \\
\hline Textures & $\begin{array}{l}\text { Cr minerals in well-formed } \\
\text { crystals. Fe-Ni-Cu sulfides } \\
\text { are mutually intergrown } \\
\text { anhedral crystals, forming } \\
\text { small ovate blebs. }\end{array}$ & $\begin{array}{l}\text { Serpentine and magnetite } \\
\text { replace olivine in ultramafic } \\
\text { rocks. Magnetite tends to } \\
\text { form veinlets and, where } \\
\text { sulfides are present, forms } \\
\text { rims around sulfide blebs. } \\
\text { Later-formed tremolite has } \\
\text { fine magnetite lamellae } \\
\text { inclusions. }\end{array}$ & $\begin{array}{l}\text { Chlorite, quartz (epidote, } \\
\text { albite) form as alterations of } \\
\text { silicate minerals. Sulfides, } \\
\text { arsenides, and sulfates deposit } \\
\text { in veins or open spaces, } \\
\text { cross-cutting earlier-formed } \\
\text { minerals. Sulfides and } \\
\text { arsenides also replace earlier } \\
\text { sulfides (e.g., As-bearing Ni } \\
\text { minerals gersdorffite and } \\
\text { nickeline replace the As-free } \\
\text { Ni mineral pentlandite). }\end{array}$ & $\begin{array}{l}\text { Earlier-formed sulfides and } \\
\text { arsenides readily corrode } \\
\text { along outer grain margins to } \\
\text { hydrous Fe oxides and Mn } \\
\text { oxides. Silicate minerals } \\
\text { often alter to clay minerals. } \\
\text { Cr minerals largely unaffected } \\
\text { except for physical } \\
\text { displacement of small } \\
\text { grains along surfaces. }\end{array}$ \\
\hline Temperature Range & $1,200^{\circ} \mathrm{C}-900^{\circ} \mathrm{C}$ & $600^{\circ} \mathrm{C}-300^{\circ} \mathrm{C}$ & $500^{\circ} \mathrm{C}-100^{\circ} \mathrm{C}$ & $25^{\circ} \mathrm{C}$ \\
\hline
\end{tabular}

Figure 18. Summary of evidence for geogenic origin of metals and metalloids. 
- Stage II: Metamorphic transformation of primary ultramafic silicate minerals olivine and pyroxene produced serpentine and magnetite (finer-grained than the igneous Cr-bearing magnetite), with metamorphic magnetite forming rims around earlier-formed (magmatic) pentlandite, pyrite, and chalcopyrite.

- Stage III: Hydrothermal alteration of rocks and associated hydrothermal deposition of additional sulfide minerals, especially in fractures, resulted in the enrichment in rocks at the site and surrounding area in a variety of metals including $\mathrm{As}, \mathrm{Ba}, \mathrm{Cu}, \mathrm{Fe}, \mathrm{Mn}, \mathrm{Pb}, \mathrm{Sb}$, and $\mathrm{Zn}$. This process appears to account for many of the minerals listed in Table 1 (Section 4.3), including arsenopyrite, barite, galena, gersdorffite, nickeline, sphalerite, and some of the chalcopyrite. Ni was incorporated in several of these minerals, although it is not clear whether $\mathrm{Ni}$ was introduced with the hydrothermal fluids or was simply remobilized from pre-existing (magmatic) pentlandite. Examples of hydrothermal alteration minerals and textures (e.g., the quartz-chlorite mineralogy in an ultramafic precursor rock) are relatively abundant in the rocks at the site and surrounding area, as is evidence of substantial metasomatism of metals and metalloids into the altered and mineralized rocks.

- Stage IV: Uplift and erosion exposed the area to weathering, and weathering of sulfides and arsenides proceeded readily in the near-surface environment, producing hydrous Fe oxides and Mn oxides observed on exposed surfaces and in open fractures and as well as in the rock matrix; this process has concentrated $\mathrm{As}, \mathrm{Ni}$, and most other metals and metalloids, especially in weathered coatings.

The effects of the regional hydrothermal mineralization and subsequent modification (by further alteration and weathering) have resulted in geogenic As enrichment in both site and area rocks well above global average concentrations for the three rock groupings of $1.5 \mathrm{mg} / \mathrm{kg}$ for felsic (granitic), $1.9 \mathrm{mg} / \mathrm{kg}$ for mafic (intermediate), and $1.5 \mathrm{mg} / \mathrm{kg}$ for ultramafic rocks [15]. This idea is also supported by characteristically high As in the waters and minerals of geothermal and hydrothermal systems worldwide as part of a suite of other metals and metalloids at high concentrations [16] [17] [18] [19].

Rock textures show a sequence of high to low temperature deposition, with minerals containing $\mathrm{As}, \mathrm{Ni}$, and $\mathrm{Cr}$ in their mineral formulas having formed early, during the magmatic or hydrothermal phases; the sulfides and arsenides are commonly observed in thin sections and in the microprobe to be surrounded by symmetrical weathering rims of hydrous Fe oxide, within which the sulfide and arsenide minerals and their contained metals and metalloids are largely absent. This texture indicates that 1 ) As and $\mathrm{Ni}$ are concentrated in reduced-phase minerals likely unrelated to anthropogenic activities, which instead would have produced oxidized species; and 2) As and $\mathrm{Ni}$ in the center of these grains were deposited earlier geologically.

Localized concentrations of metals and metalloids in weathered coatings and fracture fillings were significantly elevated above concentrations in unaltered ultramafic and felsic rocks. These accumulations developed due to readily wea- 
thered sulfide and arsenide minerals in the thick vadose zone (about $20 \mathrm{~m}$ ); relatively abundant fractures in the otherwise low-permeability igneous rocks; and seasonally intense precipitation in a moderately warm climate.

In the case of $\mathrm{Cr}$, the most concentrated forms of this element are the spinel minerals Cr-bearing magnetite and chromite. These oxide minerals are very stable under near-surface weathering, as evidenced by the lack of weathered coatings on spinel grains in thin sections, as well as the presence of spinels in segregated samples of weathered coatings. As a result, in contrast to the pattern for As and $\mathrm{Ni}$, there has been limited chemical weathering of $\mathrm{Cr}$ minerals (see Table 2), and much of the $\mathrm{Cr}$ along weathered surfaces and fractures may be present due to the transport (or passive accumulation) of broken grains of primary spinel minerals, rather than due to chemical weathering.

Patterns of hydrothermal alteration and deposition are similar at on-site and off-site locations, based on similar mineralogy of sulfide and arsenide minerals that are the source of the elements concentrated as adsorbed phases on hydrous Fe oxides. EMP quantification shows that the highest As concentration (except for small individual arsenide minerals like nickeline) was $5.9 \%(59,000 \mathrm{mg} / \mathrm{kg})$, in off-site hydrous Fe oxide from a sample $1.5 \mathrm{~km}$ from the site.

The elevated concentrations of metals and metalloids in weathered coatings and fracture fillings represent low-temperature, near surface origins, and could conceivably have originated from site sources. However, the observations of nearly identical textures and metal and metalloid concentrations, and degrees of enrichment relative to unaltered rocks in on-site and off-site weathered coatings, all suggest that the mode of formation of the on-site and off-site concentrations and coatings was similar, and that most or all of the on-site concentrations were indeed probably due to natural processes.

Taken together, these lines of evidence provide compelling evidence that the concentrations of As, $\mathrm{Cr}, \mathrm{Ni}$ and other metals and metalloids at the site are naturally occurring, and are due to a set of geological circumstances involving: 1) the initial concentrations of metals in ultramafic igneous rocks; followed by 2) some redistribution of metals during metamorphism; 3) hydrothermal alteration and deposition of a different set of metals and metalloids on a regional scale; and 4) breakdown of readily weathered sulfides and arsenides, with subsequent adsorption of metals onto hydrous Fe oxides. The patterns of metal distribution, textures, and mineral abundance are similar on the case study site and in the surrounding area. Thus, the geogenic sources of metals and metalloids can fully account for the elevated concentrations of $\mathrm{As}, \mathrm{Cr}, \mathrm{Ni}$, and other metals and metalloids reported in confirmation samples from the site.

\section{Summary of Investigative Approach}

Sites exhibiting elevated levels of metals and metalloids are often considered contaminated based on the concentrations present, without fully considering geologic context and other evidence regarding whether the source of the metals 
and metalloids is geogenic or anthropogenic. Remediation of sites exhibiting only geogenic "contamination" may not only be inappropriate, but likely also ineffective. For sites needing assessment of whether metals and metalloids may be present due to natural geologic processes (geogenic), an effort based solely on sampling of site media and the subsequent statistical analysis of results to determine background concentrations and to establish the presence and extent of contamination may well prove inadequate, especially in cases where site geology is heterogeneous and mineralization is present. At such sites, traditional environmental methods of assessment may not be up to the task of evaluating the source(s) of metals and metalloids. Instead, the suite of geochemical methods presented above will give a qualified investigative team, the tools necessary to assess the origin of the metals and metalloids, whether geogenic or anthropogenic, or a combination of sources.

The primary geochemical methods are readily employed in the field (direct observation, PLM, XRF, and XRD), and several (XRF and XRD), having been significantly refined in the last few years, have achieved a level of accuracy sufficient for most applications. Only EMP cannot be used in the field, but once polished sections are prepared, even this tool can be applied relatively quickly to provide information pertinent to determining the geogenic or anthropogenic origin of site metals and metalloids.

Ideally, the question of geogenic origin should be evaluated using multiple lines of evidence, including: 1) documentation of the presence of any nearby mines or economic mineral prospects (the alteration halo around certain mineral deposits can be several kilometers in diameter or greater); 2) characterization of the distribution of site metals and metalloids and whether they are preferentially associated with a specific formation, lithology, mineralogy, alteration type, or set of geological structures; 3) sampling and documentation of locations near the site that have geological formations and features (mineralogy, etc.) correlative with those of the site, to determine whether similar enrichment exists off site; and/or 4) characterization of the conditions of formation of site minerals that contain anomalous levels of metals and metalloids (i.e., temperature, pressure, redox, time sequence of mineral formation). Our investigation for the case study site yielded positive answers along all four of these lines of evidence, providing a significant body of evidence supporting the geogenic origin of elevated metals and metalloids at the site.

\section{Acknowledgements}

The authors would like to thank Rachel Hess for her editing of this manuscript.

\section{References}

[1] U.S. Environmental Protection Agency (2002) Role of Background in the CERCLA Cleanup Process, OSWER 9285.6-07P, Office of Emergency and Remedial Response, April.

[2] U.S. Environmental Protection Agency (2002) Guidance for Comparing Back- 
ground and Chemical Concentrations in Soil for CERCLA Sites, EPA 540-R-01-003, OSWER 9285.7-41, Office of Emergency and Remedial Response, Washington, DC 20460, September.

[3] U.S. Environmental Protection Agency (1996) Method 3050B Revision 2, Final Update 3 to the Third Edition of the Test Methods for Evaluating Solid Waste, Physical/Chemical Methods, EPA publication SW-846.

[4] U.S. Geological Survey (2017) Geology of the San Gabriel Mountains, Transverse Ranges Province.

https://geomaps.wr.usgs.gov/archive/socal/geology/transverse_ranges/san_gabriel_ mtns/index.html

[5] Vinogradov, A.P. (1959) The Geochemistry of Rare and Dispersed Chemical Elements in Soils. 2nd Edition, Consultants Bureau Enterprises, New York.

[6] U.S. Environmental Protection Agency (2007) Method 6200 Field Portable X-Ray Fluorescence Spectrometry for the Determination of Elemental Concentrations in Soil and Sediment.

[7] Beccaluva, L., Emiliani, F., Venturelli, G. and Zerbi, M. (1973) Ca, Fe, Mg, Mn, Cr, $\mathrm{Ni}$, Co Distribution in Some Ultramafic Rocks Outcropping in the Northern Apennines with Some Geological Remarks. Ateneo Parmense-Acta Naturalia (Parma), 9, 69-98.

[8] Ghatak, A., Basu, A. and Wakabayashi, J. (2012) Elemental Mobility in Subduction Metamorphism: Insight from Metamorphic Rocks of the Franciscan Complex and the Feather River Ultramafic Belt, California. International Geology Review, 54, 654-685. https://doi.org/10.1080/00206814.2011.567087

[9] Oze, C., Fendorf, S., Bird, D. and Coleman, R. (2004) Chromium Geochemistry of Serpentine Soils. International Geology Review, 46, 97-126. https://doi.org/10.2747/0020-6814.46.2.97

[10] Venturelli, G., Contini, S., Bonazzi, A. and Mangia, A. (1997) Weathering of Ultramafic Rocks and Element Mobility at Mt. Prinzera, Northern Apennines, Italy. Mineralogical Magazine, 61, 765-778.

[11] Philpotts, A. and Ague, J. (1990) Principles of Igneous and Metamorphic Petrology. 2nd Edition, Cambridge Univ. Press, Cambridge, UK.

[12] Anthony, J., Bideaux, R., Bladh, K. and Nichols, M. (Eds.) (1990) Handbook of Mineralogy: Volume 1 Elements, Sulfides, Sulfosalts. Mineralogical Society of America, Chantilly, VA 20151-1110, USA. http://www.handbookofmineralogy.org/

[13] Naldrett, A. (2004) Magmatic Sulfide Deposits: Geology, Geochemistry and Exploration. Springer, Berlin. https://doi.org/10.1007/978-3-662-08444-1

[14] Barnes, S. and Lightfoot, P. (2005) Formation of Magmatic Nickel Sulfide Deposits and Processes Affecting Their Copper and Platinum Group Element Contents. In: Hedenquist, J., Thompson, J., Goldfarb, R. and Richards, J., Eds., Economic Geology $100^{\text {th }}$ Anniversary Volume, 179-213.

[15] Smedley, P. and Kinniburgh, D. (2002) A Review of the Source, Behaviour and Distribution of Arsenic in Natural Waters. Applied Geochemistry, 17, 517-568. https://doi.org/10.1016/S0883-2927(02)00018-5

[16] Guo, Q., Liu, M., Li, J. and Zhou, C. (2017) Geochemical Genesis of Arsenic in the Geothermal Waters from the Rehai Hydrothermal System, Southwestern China, from 15th Water-Rock Interaction International Symposium, WRI-15. Procedia Earth and Planetary Science, 17, 49-52. https://doi.org/10.1016/j.proeps.2016.12.024

[17] Boyle, R. (1974) Elemental Associations in Mineral Deposits and Indicator Elements 
of Interest in Geochemical Prospecting. Geological Survey Paper 74-45, Energy Mines and Resources Canada.

[18] Berger, B. and Silberman, M. (1985) Relationships of Trace Element Patterns to Geology in Hot-Spring Type Precious Metal Deposits. In: Berger, B. and Bethke, P., Eds., Geology and Geochemistry of Epithermal Systems, Reviews in Economic Geology, Vol. 2, 233-248.

[19] Binquin, Z., Jinmao, Z., Liscin, Z. and Yascin, Z. (1986) Mercury, As, Sb, Bi and B as Geochemical Indicators for Geothermal Areas. Journal of Geochemical Exploration, 25, 379-388. https://doi.org/10.1016/0375-6742(86)90085-3

[20] Ravenscroft, P., Brammer, H. and Richards, K. (2009) Arsenic Pollution: A Global Synthesis. Wiley Blackwell, Chichester, UK. https://doi.org/10.1002/9781444308785

[21] Sen, T., Mahajan, S. and Khilar, K. (2011) Adsorption of $\mathrm{Cu}^{2+}$ and $\mathrm{Ni}^{2+}$ on Iron Oxide and Kaolin and Its Importance on $\mathrm{Ni}^{2+}$ Transport in Porous Media. Colloids and Surfaces A: Physicochem Engineering Aspects, 211, 91-102.

https://doi.org/10.1016/S0927-7757(02)00235-2 


\section{Supplemental Information}

\section{Visual Classification of Rocks and Minerals (see text, Section 3.1)}

Field identification of minerals is performed through direct observation of a variety of attributes, including crystal form and habit, color, hardness, magnetism, luster (e.g., glassy, waxy, metallic), streak (color of the powdered mineral [tested by abrading it on a ceramic plate]), cleavage (one or more fracture planes that intersect at characteristic angles), weathering features (e.g., metal sulfides such as pyrite are relatively easily oxidized), and the other minerals or rock types with which they are associated.

Once the predominant minerals are identified in geologic samples, the samples can then be assigned to rock classes and specific rock names. For example, the igneous rock class can be identified by the presence of interlocking crystals that are relatively pristine (as opposed to constituent grains of sedimentary rocks that are abraded due to erosion during sediment transport). The specific rock type of granite (one of the most common rock types) consists of major proportions of the generally light-colored minerals quartz, potassium feldspar, and plagioclase feldspar, with lesser proportions of dark minerals, commonly hornblende or biotite. All these mineral and rock attributes are relatively apparent in the field and, taken together, can be used for mineral and rock identification.

\section{XRF Analysis (See text, Section 3.2)}

$\mathrm{X}$-ray fluorescence (XRF) analyses for major elements should be conducted using protocols consistent with EPA Method 6200 [6], or similar industry-standard method to ensure the collection of high quality, defensible data. Best practices for analyzing geological media by XRF are outlined below:

- Start up the instrument and allow it to fully warm up.

- After initial warm-up, standardize the XRF instrument using a "coin" or other sample of known composition supplied by the manufacturer.

- Once standardized, initial calibration verification (ICV) should be performed using a blank composed of synthetic quartz and two or more standards traceable to the National Institute of Standards and Technology (NIST) or equivalent standards agency. The standards should be selected to represent the range of anticipated concentrations of the primary metals and metalloids of interest at the site.

- The XRF should report no detectable metals and metalloids of interest in the synthetic quartz blank, and should report known values for the standards within the required percent relative standard deviation (\%RSD) established for the primary metals and metalloids of interest (typically around 20\%). Once the ICV is successfully completed, begin sample analysis.

- Continuing calibration verification (CCV) should be performed every 4 hours or approximately every 10 samples, and closing calibration verification performed at the end of each day. Alternatively, a control chart approach may be used for analysis of a large number of samples. This approach re- 
quires more extensive analysis during initial calibration (typically a minimum of 10 analyses for each standard), but just single CCV and closing calibration analyses per standard as long as the results stay within the warning limits established for the control chart (typically 2-sigma warning limits and 3-sigma failure limits).

- Samples should be run in triplicate, and \%RSDs calculated for the primary metals and metalloids of interest and compared with the same acceptance criteria established for the standards. If one or more of the primary metals and metalloids of interest fails to achieve the required \% RSD, analysis of the sample should be repeated.

The above procedures were used for samples from the case study site, selected following visual examination and hand screening by XRF as those samples most likely to contain the metals and metalloids of interest. Around 250 samples from the site and surrounding area were analyzed using an Olympus Corporation (Olympus) X-5000 XRF for major and minor elements. Most of these samples represented rock samples, but some of the samples represented mineral coatings scraped from rock surfaces.

\section{XRD Analysis (see text, Section 3.3)}

Powdered $\mathrm{x}$-ray diffraction (XRD) can be performed in the field using an innovative portable XRD from Olympus, the TERRA Portable XRD System (Terra). This unit is based on technology developed by the National Aeronautics and Space Administration (NASA) used on the Mars Rover. The unique feature of this unit is its method of sample agitation, allowing for the simultaneous analysis of all angles rather than rotating the sample or the detector. This allows the instrument to fit into a briefcase-sized container. The quality of the diffraction pattern generated using the Terra instrument is dependent on sample preparation and the time allowed for the unit to collect a series of individual "shots". Samples should be powdered, and then sieved to pass a 100-mesh (0.149-millimeter $[\mathrm{mm}])$ sieve and be retained on a 200-mesh $(0.074-\mathrm{mm})$ screen. Care should be exercised to avoid biasing the sample by uneven grinding, inadvertently resulting in segregation of some mineral phases due to preferential sizes. However, for complex samples, physical separation of the sample based on magnetism, density or other physical attributes can help reduce the number of mineral phases present in each sub-sample, making the resulting diffraction patterns easier to analyze. XRD analyses performed on a single mineral phase such as quartz can produce a definitive pattern in as little as 5 to 10 minutes. Rock samples with multiple mineral phases benefit from analyses of approximately 2 hours to produce clean distinct diffraction patterns. The diffraction patterns can be analyzed using XPowder or other commercial diffraction analysis software to compare the sample diffraction pattern with diffraction patterns of known mineral phases.

Over 60 samples from the case study site were analyzed by XRD to support determination of primary mineralogy in samples of rocks and mineral coatings. The XRD proved valuable in identifying fine alteration products such as clinochlore (a variety of chlorite), characteristic of chloritic alteration of an ultra- 
mafic rock, as well as other fine mineral phases such as the clay minerals kaolinite and montmorillonite. Figure 12 (see Section 4.2.4 of the main text) shows the XRD pattern for a sample with significant alteration products, including clinochlore and montmorillonite. The XRD results evaluated in conjunction with the XRF results and microscopic examination of thin-sections enhances the interpretation of more complex hydrothermally altered or weathered rocks.

\section{Mineral Identification Using PLM (see text, Section 3.4)}

Polarized light microscopy (PLM) employs the use of 30-micron-thick slices of rock mounted on 24-by-36-mm glass slides, and the examination of these slides in a polarizing microscope. At this thickness, most minerals, including most silicates (quartz, feldspars, clay minerals, etc.) are transparent or translucent. The use of two sets of polarizers (above and below the thin section) enables the investigator to view minerals' differing behavior when polarized light passes through them. A variety of characteristics of minerals can often be recognized by PLM that, taken together, can be used to distinguish most rock-forming and ore-forming minerals. These include crystal form; color; cleavage; association with specific minerals or rock types; presence of inclusions (small grains of other minerals within the larger mineral grain) or intergrowths with specific minerals; crystal twinning (two or more crystal orientations in a single compound crystal); alteration products (e.g., sulfide minerals tend to oxidize easily); and two properties related to polarized light passing through the mineral: pleochroism (characteristic change in color when the mineral is rotated on the microscope stage within plane-polarized light) and birefringence (interference color of the mineral due to double-refraction of light passing through the mineral grain when both the polarizers are used).

For polished thin sections, one side of the thin section is polished. The reflecting capability of the polarizing microscope can be used to view characteristics of opaque minerals on the polished side of the slides. Identifying traits of opaque minerals include many of the same attributes observed with minerals that transmit light, specifically crystal form, cleavage, color, association with other specific minerals or rock types, presence of inclusions and intergrowths, crystal twinning, alteration products, bi-reflectance, and anisotropy (the latter two are analogous to the pleochroism and birefringence of translucent minerals). Two additional properties of opaque minerals can be distinctive for identification: hardness, which can often be inferred by how it has resisted abrasion and polishing, with harder minerals standing higher on the thin section (in positive relief) compared to softer minerals; and reflectivity, which is the proportion of light reflected back by the mineral compared to the intensity of the incident light.

For unconsolidated material such as weathered coatings, thin sections were prepared as grain-mounts, whereby grains chipped from the coatings were embedded in resin, cut, and polished, before making the thin section in the same manner as for rock samples.

Mineral Identification and Element Quantification Using EMP (see text, 


\section{Section 3.5)}

The electron microprobe (EMP) measures both the wavelength (wavelength-dispersive spectroscopy [WDS]) and energy (energy-dispersive spectroscopy [EDS]) of the $\mathrm{x}$-rays, and is capable of both semi-quantitative and quantitative measurement of element concentrations.

Examination of polished thin sections in an EMP provides multiple real-time analyses, including:

- Backscatter electron (BSE) imaging-electrons that are reflected (back-scattered) from interactions with atoms in the specimen. These images correlate with the density of the mineral grains.

- Reflected light imaging-shining light on the sample and capturing the light reflected off its surface.

- Semi-quantitative analysis by EDS of specific mineral grains and portions of grains to identify all major elements.

- X-ray mapping of a specific area using WDS to determine the distribution of multiple target elements.

- Wavelength scanning by WDS to confirm the presence of specific elements in the cases where interferences may obscure the identification of a critical element.

In addition, EMP analysis can quantitatively measure elemental content of specific mineral grains to verify composition and mineralogy using WDS. 